\title{
Copper electrodeposition on alkanethiolate covered gold electrodes*
}

\author{
Cavalleri, O ; Bittner, A M ; Kind, H ; Kern, K ; Greber, T
}

DOI: https://doi.org/10.1524/zpch.1999.208.part_1_2.107

Posted at the Zurich Open Repository and Archive, University of Zurich

ZORA URL: https://doi.org/10.5167/uzh-154059

Journal Article

Published Version

Originally published at:

Cavalleri, O; Bittner, A M; Kind, H; Kern, K; Greber, T (1999). Copper electrodeposition on alkanethiolate covered gold electrodes*. Zeitschrift für Physikalische Chemie, 208(1-2):107-136.

DOI: https://doi.org/10.1524/zpch.1999.208.part_1_2.107 


\title{
Copper Electrodeposition on Alkanethiolate Covered Gold Electrodes*
}

\author{
By O. Cavalleri, A. M. Bittner**, H. Kind, K. Kern \\ Institut de Physique Expérimentale, Ecole Polytechnique Fédérale de Lausanne, \\ CH-1015 Lausanne, Switzerland \\ and T. Greber
}

Physik-Institut, Universität Zürich, CH-8057 Zürich, Switzerland

(Received December 1, 1997; accepted December 23, 1997)

\section{Cyclic voltammetry / Film growth /}

Scanning tunnelling microscopy (STM) / Single crystal electrode / Surface structure / Thiols / X-ray photoelectron spectroscopy (XPS)

\begin{abstract}
We have investigated the structure and thermal dynamics of alkanethiolate layers on $\mathrm{Au}(111)$ with variable temperature scanning tunnelling microscopy (STM), X-ray photoelectron spectroscopy (XPS) and voltammetry. The results build the basis for a study of electrodeposition of copper on alkanethiolate-covered $\mathrm{Au}(111)$. Electrodeposition has been studied as a function of the thiolate chain length, the deposition potential and the temperature. Time-resolved in situ STM and voltammetry, both at temperatures up to $345 \mathrm{~K}$, and XPS of emersed samples showed that copper can - depending on the deposition potential - either form nanometer-sized islands or layers, both without destruction of the thiolate. We propose a mechanism where copper penetrates the thiolate layer. The slow deposition rate is determined only by kinetic factors since $\mathrm{Cu} / \mathrm{Cu}^{2+}$ exchange processes cannot operate. Finally we discuss the role of thiolates as preadsorbed surfactants.
\end{abstract}

\section{Thiolate layers and the electrodeposition of metals}

Certain chemical elements or molecules, especially soft bases such as iodide, bromide, sulphide, carbon monoxide and cyanide, are known to bind with exceptional strength to noble metal surfaces. In electrochemical terms, the substances adsorb specifically. Such adlayers are often densely packed, hence the atoms or molecules prefer (quasi)-hexagonal arrangements [1-7].

* Presented at the 5. Ulmer Elektrochemische Tage on "Fundamental Aspects of Electrolytic Metal Deposition”, June 23-24, 1997.

** Corresponding author, e-mail: alexander.bittner@ipe.dp.epfl.ch 
The adlayer geometry is determined by the interplay of adsorbate-substrate forces that tend to direct the adsorbing atoms to places that offer a strong bond (often hollow sites) and interadsorbate forces that can be attractive or repulsive. More complex, but also much more versatile, are thiolate adsorbates. Alkanethiols $\mathrm{CH}_{3}\left(\mathrm{CH}_{2}\right)_{n-1} \mathrm{SH}$ (' $\mathrm{C}_{n}$ thiols') form strongly adsorbed, ordered thiolate layers $\mathrm{CH}_{3}\left(\mathrm{CH}_{2}\right)_{n-1} \mathrm{~S} /$ substrate [8-10]. Although the adsorption process does not differ principally from the above-mentioned cases, the term 'self-assembly' is employed to point out that thiolate interadsorbate forces are very strong - long adsorption times are necessary to assemble an ordered structure where the alkyl chains align parallel. Up to now, mainly the $\mathrm{Au}(111)$ substrate was used; its reconstruction is readily lifted during the adsorption.

Several studies of vacuum metal deposition on thiolate-covered metal substrates were conducted; Jung and Czanderna compiled a valuable review [11]. The electrodeposition of metals, e.g. copper, on thiolate layers is technically much simpler, but more difficult to interpret: one has to consider the electrode potential. Especially the $\mathrm{Cu}^{2+} / \mathrm{Cu}$ equilibrium (Nernst) potential is important. Positive of that point, copper can only deposit in a single layer and only on some special substrates (underpotential deposition, UPD) [1217]. Negative of it, normal copper bulk deposition takes place on any substrate (overpotential deposition, OPD). Electrodeposition of $\mathrm{Cu}^{2+}$ in the OPD range often results in 3D growth of copper on metal substrates as e.g. found with in situ STM [12a, 18-23].

A similar situation shows up when copper is deposited on alkanethiolate-covered $\mathrm{Au}(111)$ deep in the OPD range: large copper nodules with diameters in the $100 \mathrm{~nm}$ range develop [24, 25]. In contrast, we worked at moderate overpotential which results in a complex scenario that can be investigated with in situ STM [26-29]. We found a pseudo-layer-by-layer growth [27], i.e. one layer is almost finished before the next one starts to grow. Such a behaviour is very rare on bare metal electrodes (some exceptions of this rule were found with in situ STM [12a, 19, 30-32]). On the other hand, it is well known that a metal surface covered by strongly adsorbing substances can indeed incite such a 2D growth. Such substances are called 'surfactants'; in the simplest case, one of the above-mentioned strongly adsorbing atomic ions is a surfactant, as known for the electrodeposition of silver on iodide-covered $\mathrm{Pt}(111)$ [33]. Usually, the metal penetrates the halogenide layer; the topmost structure can be addressed as a metal-halogenide coadsorbate $[17,33-36]$. In the presence of a large surfactant molecule, crystal violet, in the electrolyte, an STM study indeed proved the $2 \mathrm{D}$ growth scenario $[20,22]$. This situation is already close to the technical application where 'brighteners' are added to metal plating baths to yield smooth deposits.

In the UPD range where island formation on bare metal substrates is a rare phenomenon (but see [37] and [38]), we were able to deposit copper 
islands with diameters in the nm range on alkanethiolate-covered $\mathrm{Au}(111)$. This process is a relatively simple method for building nanometer-sized metal structures [29].

An often neglected parameter in electrochemical STM studies is the temperature on which we shall concentrate in this paper. As we will show in section 3, heating induces several stages of disorder in thiolates, progressing from the (methyl) end group towards the substrate. First, the methyl rotation is activated at $T \geq 100 \mathrm{~K}$ as revealed by helium diffraction studies [10]. Above $200 \mathrm{~K}$ the infrared probing of the methylenes' scissors vibration suggests progressive unlocking of the alkyl twist (a rotation around either an $\mathrm{S}-\mathrm{C}$ or a $\mathrm{C}-\mathrm{C}$ bond) and development of gauche defects in the otherwise all-trans configured chains [39]. This behaviour compares well with that of self-assembled thiolates on gold nanoparticles [40] and that of melting bulk alkanes [41]. Heating above $300 \mathrm{~K}$ as we used for this study can even affect the $\mathrm{Au}-\mathrm{S}$ bond: boundaries between different ordered thiolate domains move or vanish, mass transport of the substrate occurs and finally leads to the healing of the typical substrate vacancies. These vacancies are defects appearing during the self-assembly [42-45].

A discussion of the phenomena occurring upon heating thiolate layers (see section 3.2) will provide a valuable basis for understanding our most recent experiments where we followed the electrodeposition of copper at elevated temperatures with in situ STM (see section 4). Electrochemical STMs were up to now never operated above $300 \mathrm{~K}$ albeit deposition studies should be of greatest importance for the understanding of technical metal plating which is mostly carried out well above $300 \mathrm{~K}$. We will also show that the temperature can be used as an extra parameter for tuning the copper as well as the substrate structure (see section 4.3). Encompassing our experiments at $300 \mathrm{~K}[26,27,29]$ and the recent results, we will focus on the structure of the deposited copper in section 4.2 and additionally analyse the extremely slow deposition kinetics in section 4.4.

Our experimental methods are in situ electrochemical STM at 300 up to $345 \mathrm{~K}$, STM in nitrogen at 300 up to $370 \mathrm{~K}$, cyclic voltammetry and $\mathrm{X}$-ray photoelectron spectroscopy (XPS) of emersed samples. They will be explained in the following section.

\section{Experimental techniques}

The gold samples were prepared by evaporation of 120 to $150 \mathrm{~nm}$ gold on $570 \mathrm{~K}$ hot cleaved mica in a $10^{-5}$ mbar vacuum and then annealed for several hours at $\approx 600 \mathrm{~K}\left(2 \cdot 10^{-6} \mathrm{mbar}\right)$. Directly before starting the selfassembly, the gold films were flame annealed at very dark red glow and cooled in ethanol (p.a., Fluka). For the self-assembly, the samples were transferred into $10 \mu \mathrm{M}$ or $1 \mathrm{mM}$ ethanolic solutions of alkanethiols (Fluka) 


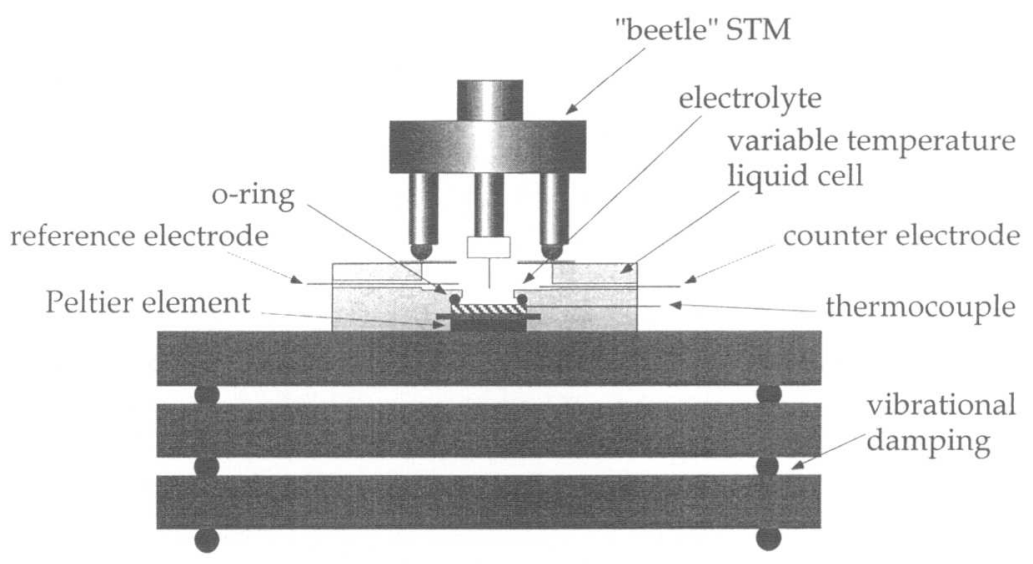

Fig. 1. Schematic drawing of the electrochemical temperature-variable STM setup.

$\mathrm{CH}_{3}\left(\mathrm{CH}_{2}\right)_{n}$, $\mathrm{SH}$ with $n=6,8,10,12,14,16$ and 18. For the experiments carried out under nitrogen, the samples were kept at $300 \mathrm{~K}$ for at least one day. For the electrochemical experiments, the following self-assembly program was used: two hours $300 \mathrm{~K}$, two days ca. $325 \mathrm{~K}$, thereafter several more days (or in rare cases weeks) $300 \mathrm{~K}$. All samples were emersed, rinsed with ethanol and quickly used. STM measurements were performed as described in [29]. As shown in Fig. 1, a new feature is a Peltier element (operated in the heating configuration) that we coupled with a thin copper spacer to the bare side of the mica sample, thus attaining a stable sample and electrolyte temperature (less than $1 \mathrm{~K}$ change per hour). The goldcovered side was in contact with the electrolyte, $50 \mathrm{mM} \mathrm{H}_{2} \mathrm{SO}_{4}$ (p.a., Fluka) +0 or $1 \mathrm{mM} \mathrm{CuSO}_{4}$ (p.a., Fluka), either in water (Millipore ${ }^{(p)}$ ) or - for the high-temperature experiments - in 2: $1 \mathrm{HOCH}_{2} \mathrm{CH}_{2} \mathrm{OH}$ (1,2-ethandiol, ethylene glycol, p.a., Fluka): $\mathrm{H}_{2} \mathrm{O}$. Ethylene glycol very effectively stops the otherwise quick evaporation. The reference was a copper wire, etched in $\mathrm{HNO}_{3}$ and rinsed with water shortly before use. The sample was mounted in a PCTFE STM cell equipped with a Pt counter electrode. For the XPS sample preparation as well as for the redox pair measurements, exactly the same set-up was used. The redox electrolytes contained $\mathrm{Ru}\left(\mathrm{NH}_{3}\right)_{6} \mathrm{Cl}_{3}$ (Alfa) or $\mathrm{K}_{3} \mathrm{Fe}(\mathrm{CN})_{6}(\mathrm{MicroSelect}$, Fluka) with $\mathrm{KCl}$ (p.a., Fluka) and $\mathrm{HCl}$ (p.a., Fluka) in ethylene glycol/water, and an $\mathrm{Ag} / \mathrm{AgCl}$ reference was dipped into the STM cell. All potentials are quoted with respect to the $\mathrm{Cu} / \mathrm{Cu}^{2+}$ pair in $1 \mathrm{mM} \mathrm{Cu}^{2+}$ (i.e. $0 \mathrm{mV}$ read $+250 \mathrm{mV}$ on the standard hydrogen scale and $+50 \mathrm{mV}$ on the $\mathrm{Ag} / \mathrm{AgCl}(\mathrm{KCl}$ sat.) scale). We always employed an EG\&G PAR 400 potentiostat. The potential range above $500 \mathrm{mV}$ and below $-200 \mathrm{mV}$ was usually not accessed in order to avoid oxidation and reductive destruction of the thiolate layer, respectively (see 4.3.2). STM im- 
ages are shown derivatised: steps descending from left to right show up as black lines, ascending ones as white lines. The X-ray photoelectron spectra have been performed in a VG ESCALAB 220. After removal from the liquid we mounted the samples with electrical contact and introduced them via a fast entry lock into the vacuum system. In order to minimize X-ray tube induced damage the spectrometer transmission was maximized with lowest angular resolution and an overall energy resolution of $1.4 \mathrm{eV} \mathrm{FWHM}$ on the $\mathrm{Au} 4 \mathrm{f}_{7 / 2}$ peak at $84.0 \mathrm{eV}$ binding energy. The X-ray twin anode that provides non-monochromatized $\mathrm{Mg} \mathrm{K} \alpha(1253.6 \mathrm{eV})$ radiation was retracted and run with $140 \mathrm{~W}$ input power. With respect to the maximum flux these settings lower the resulting electron flux from an aluminum sample by a factor of 0.3 to $15 \mathrm{nA} / \mathrm{cm}^{2}$. The emission angle was $0^{\circ}$ (normal emission) and $80^{\circ}$ (grazing emission). From the comparison of the two emission directions the vertical structure of the chemical composition of the $(\mathrm{Cu}) /$ $\mathrm{CH}_{3}\left(\mathrm{CH}_{2}\right)_{n-1} \mathrm{~S} / \mathrm{Au}(111)$ system can be inferred.

\section{Alkanethiolate layers on $\mathrm{Au}(111)$}

In order to develop a basis for understanding the complex copper deposition process we shall here present studies of alkanethiolate layers on Au(111) under vacuum, in nitrogen, air and immersed in electrolyte, all in absence of copper.

\subsection{Structure and morphology}

Let us first focus on the chemical composition of alkanethiolate layers on $\mathrm{Au}(111)$ which can be detected with XPS. In Fig. 2 the overview spectrum of $\mathrm{CH}_{3}\left(\mathrm{CH}_{2}\right)_{17} \mathrm{~S} / \mathrm{Au}(111)$ (sample A) is shown for normal emission. The spectrum is dominated by the strong emission from the gold substrate and the $C$ 1s peak. It can be seen that the samples remain almost oxygen free although they have been exposed to air for more than $100 \mathrm{~s}$. In all details, such a spectrum is typical of the thiolate/gold system [46, 47].

In Fig. 3 the $\mathrm{Au} 4 \mathrm{f}, \mathrm{C} 1 \mathrm{~s}, \mathrm{O}$ 1s (and for comparison $\mathrm{Cu} 2 \mathrm{p}_{3 / 2}$ ) XP spectra are shown for sample $A$. The $A u 4 f_{7 / 2}$ peak is set to $84.0 \mathrm{eV}$ binding energy. The $\mathrm{C}$ 1s peak is found at $285.0 \mathrm{eV}$ and corresponds to that of polyethylene chains [48]. We show as well the spectra from grazing $\left(80^{\circ}\right)$ emission (data for carbon and oxygen are not shown since the sample holder contributes to the oxygen and some of the carbon emission). As the intensity from sulphur (not shown), the intensity of the gold signal is strongly suppressed; this is observed in presence (as in Fig. 3) and absence (not shown) of copper. The attenuation by more than one order of magnitude can only be explained by a layer model in which the thiolate covers the gold and binds with the sulphur end to the substrate. 


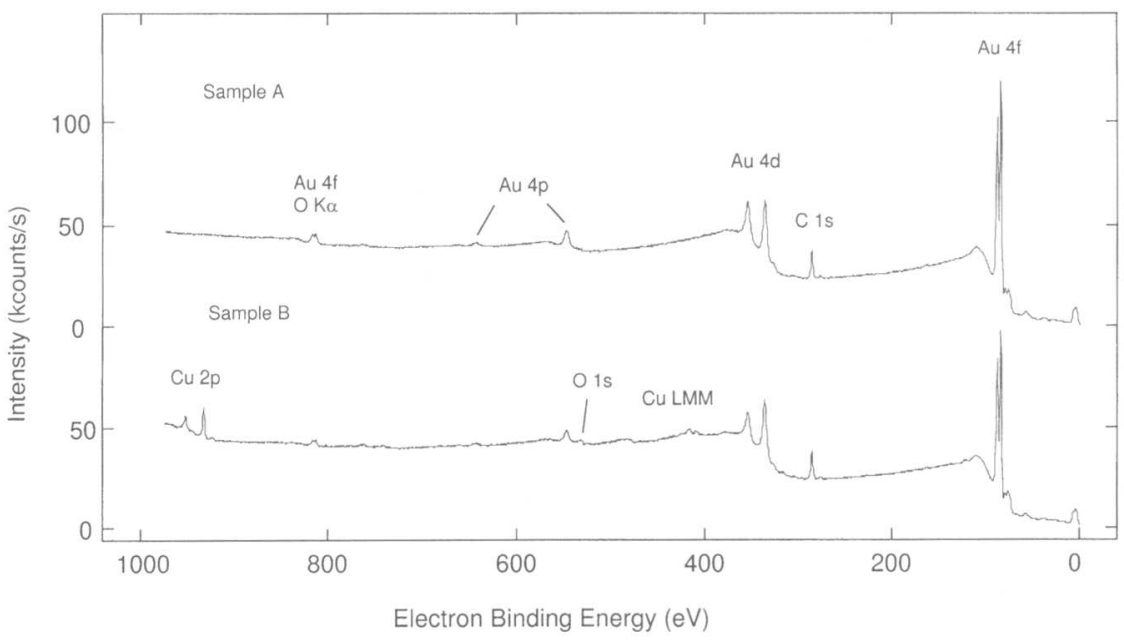

Fig. 2. Normal emission XPS of a $\mathrm{C}_{18}$ thiolate layer on $\mathrm{Au}(111)$; $\mathrm{X}$-ray source $\mathrm{Mg} \mathrm{K} \alpha$. Sample A corresponds to an untreated sample, while on sample B copper was electrochemically deposited.

In Fig. 4 the grazing emission intensity of the $\mathrm{C} 1 \mathrm{~s}$, the $\mathrm{Au} 4 \mathrm{f}$ and the $\mathrm{Cu} 2 \mathrm{p}_{3 / 2}$ level are shown as a function of exposure time to the $\mathrm{X}$-rays. While the carbon emission remains constant, the gold and the copper emission increase with the exposure time. For samples without copper deposit we do observe the same aging kinetics (not shown). This variation clearly indicates a change of the sample. The overlayer appears to become more transparent to the emission from the substrate. The gold and copper intensities perfectly fit a first order kinetics ansatz I $\propto\left(1-\beta \mathrm{e}^{-t / \tau}\right)$ where $\beta>1$ is a sensitivity factor and where $\tau$ is the time constant. Within the uncertainty of the data, the sensitivity $\beta$ and the time constant $\tau$ are independent whether copper has been deposited on the sample or not. The sensitivity $\beta$ is $0.45 \pm 0.07$ for copper and gold. $\tau$ is inversely proportional to the secondary electron flux from the sample. From the value of $\tau$ of $2 \cdot 10^{4} \mathrm{~s}$ and the secondary electron emission flux we find that the secondary electron current density from an aluminum sample times the time constants is in the order of $2 \cdot 10^{15} \mathrm{e}^{-1} / \mathrm{cm}^{2}$. This indiates that the thiolate films are very susceptible to ionizing radiation as also reported by Jäger et al. [49] (other groups found much larger time constants [50]).

Turning the attention towards the interfacial structure probed by STM, let us first note that the tunnelling currents employed (some tenths of nA) are essentially sensitive to the sulphur atom - the tip easily penetrates the thiolate chains which cannot offer local electronic states in the proper energy range [51]. The principal structure element, $\mathrm{a}(\sqrt{3} \times \sqrt{3}) \mathrm{R} 30^{\circ}$ lattice 


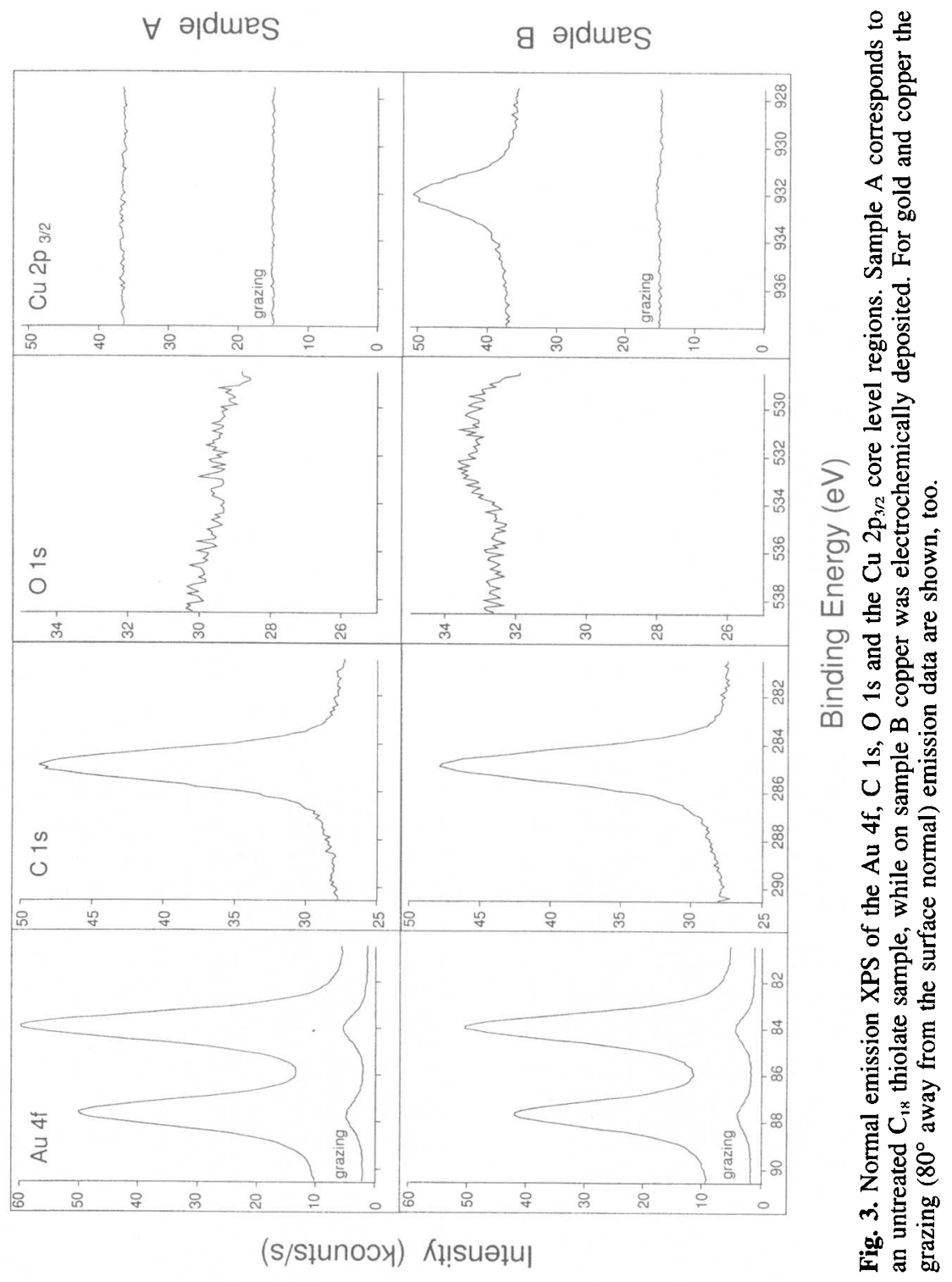

(Fig. 5), can thus be ascribed to the sulphur atoms, yielding a coverage of 0.33 . Note that the same structure was found for a sulphide adlayer adsorbed on an $\mathrm{Au}(111)$ electrode and for $\mathrm{S} / \mathrm{Au}(111)$ in vacuum [7]. However, we detected 'super-superstructures', e.g. the well-known centered $(4 \times 2)$ distri- 


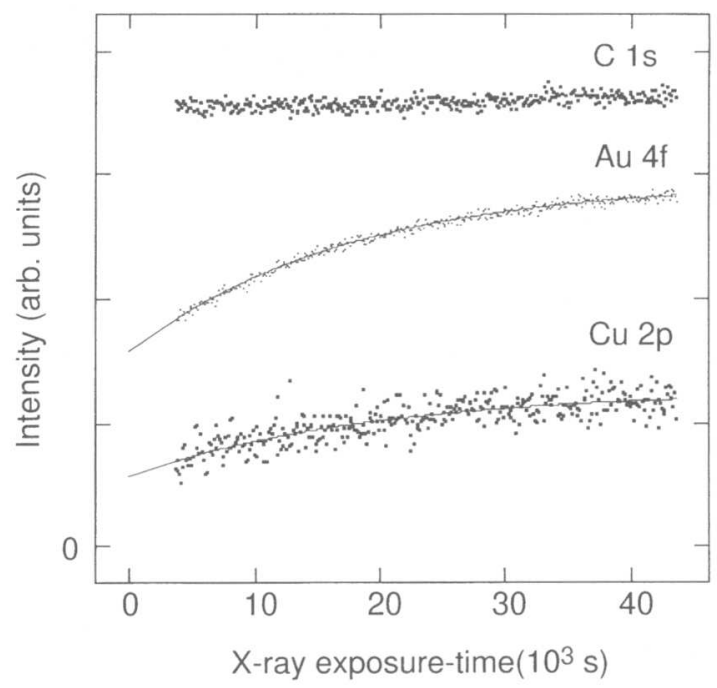

Fig. 4. Grazing photoelectron emission intensities of $\mathrm{C} 1 \mathrm{~s}$, $\mathrm{Au} 4 \mathrm{f}$ and $\mathrm{Cu} 2 \mathrm{p}_{3 / 2}\left(\mathrm{C}_{1 \times}\right.$ thiolate) as a function of exposure to the $\mathrm{Mg} \mathrm{K} x \mathrm{X}$-ray source. The solid lines in the data of copper and gold are fits to first order kinetics.

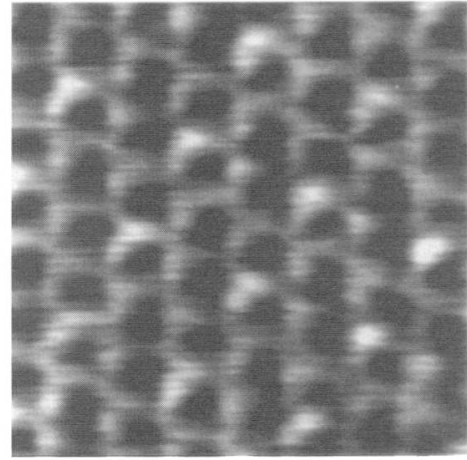

a)

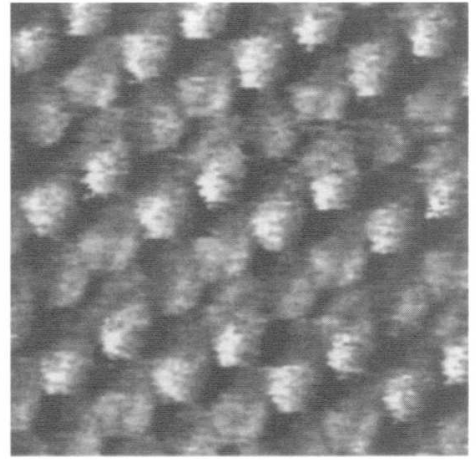

b)

Fig. 5. Molecular resolution STM images taken in nitrogen showing the $c(4 \times 2)$ pinwheel (a) and the $\mathrm{c}(4 \times 2)$ zig-zag (b) superstructures on a $\mathrm{C}_{10}$ thiolate sample. Tunneling parameters: (a) $\mathrm{I}=1.0 \mathrm{nA}, \mathrm{V}=1000 \mathrm{mV}$ : (b) $\mathrm{I}=0.6 \mathrm{nA}, \mathrm{V}=1000 \mathrm{mV}$. Image size: $3.5 \mathrm{~nm} \times 3.5 \mathrm{~nm}$.

bution (Fig. 5) of the $(\sqrt{3} \times \sqrt{3}) \mathrm{R} 30^{\circ}$ elements (in proper notation $(3 \times 2 \sqrt{3}))[10,52-55]$. At lower coverage (attainable by vapour phase dosing of thiols [56] or by heating above $370 \mathrm{~K}[57,58]$ ) and for short 


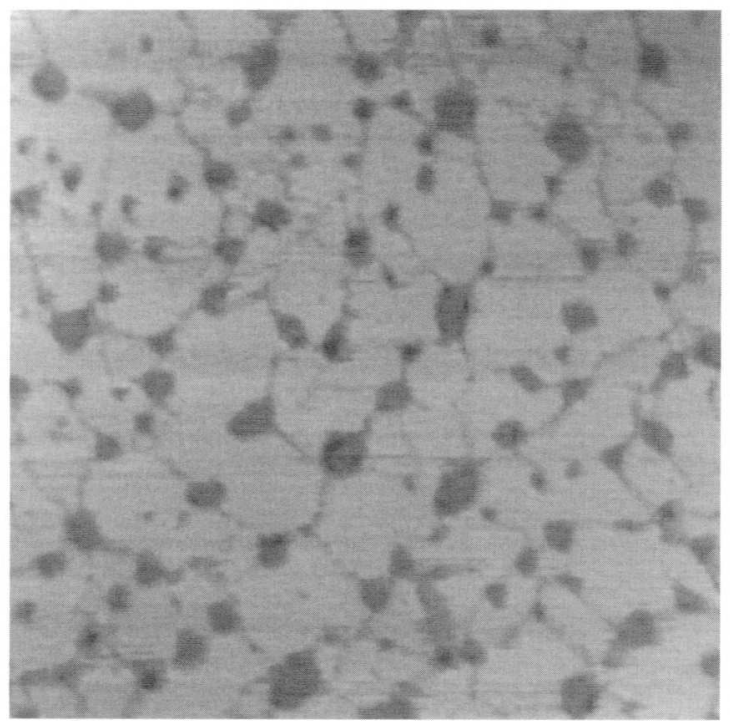

Fig. 6. STM image of a $C_{11}$ thiolate-covered $A u(111)$ surface in air. The dark lines are thiolate domain boundaries which are pinned by the substrate vacancies (dark spots). Tunneling parameters: $\mathrm{I}=0.3 \mathrm{nA}, \mathrm{V}=900 \mathrm{mV}$. Image size: $320 \mathrm{~nm} \times 320 \mathrm{~nm}$.

chain thiolates we detected striped structures [58] (see also [56, 57, 59, $60]$ ). All these structures can exist in different domains separated by domain walls. These walls show up as dark grooves of roughly half a monolayer depth and 1 to $3 \mathrm{~nm}$ width. In Fig. 6 the walls often extend between neighbouring substrate vacancies (large dark spots), but they can also terminate at other walls or at steps. During heating in nitrogen, the number of grooves in an STM image diminuishes, i.e. the average domain size increases [61].

Further healing processes that can be followed involve Ostwald ripening, coalescence and annihilation (at steps) of the vacancies [43, 45]. The latter are ascribed to etching processes [62,63] and the lifting of the $\mathrm{Au}(111)$ reconstruction and concomitant surface diffusion during the selfassembly process $[64,65]$; their surface is covered by thiolate as are all other terraces $[58,66,67]$.

Our latest experiments show that the $(\sqrt{3} \times \sqrt{3}) \mathrm{R} 30^{\circ}$ lattice, domain walls and vacancies are found also when the samples are immersed in electrolyte and kept under potential control (in situ STM). When we use the modified electrolyte based on an ethylene glycol/water mixture, we can now additionally scan the surface at elevated temperature [28]. As visualized in the image series of Fig. 7, depicting a vacancy that is rapidly filled with 
material from a nearby step, we found highly mobile surfaces already at $335 \mathrm{~K}$. The surface appeared to be more mobile than in nitrogen, probably a result of the electrochemical polarization.

Some further properties, especially the ability to transfer electrons through a thiolate layer, can be probed with cyclic voltammetry. As electrolytes we routinely used sulphuric acid either in water or in ethylene glycol/ water. In passing we note that we proved that ethylene glycol does neither affect the electrochemistry of thiolate/Au(111) nor that of the copper reduction at thiolate/ $\mathrm{Au}(111)$ and bare $\mathrm{Au}(111)$ [28]. The voltammograms are typical for nonreactive surfaces since the double layer current is smaller than for a bare metal surface. In general, the current for short chain thiolates is larger than for long chain thiolates. At higher temperatures the current rises considerably. Thus electrons can be transferred across the thiolate easier when the chain is short and the temperature high. However, one should keep in mind that the double layer could have a structure and thus capacity differing from that on bare gold.

Hence we also probed the surfaces with a redox pair, $\mathrm{Fe}(\mathrm{CN})_{6}^{3 / 4-}$. The voltammogram in Fig. 8 reveals the typical current waves that result from kinetic and diffusional limitations, but with less peak current than on bare $\mathrm{Au}(111)$. We found the same behaviour as for the double layer current mentioned above: the redox waves' current rose at high temperatures and for short chain lengths. Note that the temperature behaviour can be more complex [68]. Experiments with $\mathrm{Ru}\left(\mathrm{NH}_{3}\right)_{6}^{3 / 2+}$ normally showed a much higher current; however, the same dependence on the thiolate chain length is found (Fig. 9). To assess the findings we note that the diffusional limitation must be the same at bare and thiolated $\mathrm{Au}(111)$. The rate of the slowest (rate determining) process responsible for the thiolates' blocking behaviour can be the charge transfer across the thiolate or possibly a penetration of the complexes into the thiolate.

In the following, we shall interpret the structure and morphology of alkanethiolate-covered $\mathrm{Au}(111)$ at $300 \mathrm{~K}$. We will progress from a single molecule (sub-nm) to the mesoscopic scale $(\mu \mathrm{m})$. First, our XPS data confirm the accepted structure model of a gold surface covered by sulphurbound thiolates. The small oxygen contamination is likely due to air exposure. It may consist of adsorbed oxygen atoms (e.g. at thiolate-free defects) and/or water (difficult to remove completely in vacuum chambers). However, oxygen is a minor species on a thiolate surface, even after exposure to air.

Fig. 7. In situ electrochemical STM image sequence (time separation ca. $1 \mathrm{~min}$ ) showing the temperature induced mobility of a $\mathrm{C}_{\mathrm{b}}$ thiolate/Au(111) interface at $335 \mathrm{~K}$. Electrode potential: $300 \mathrm{mV}$ vs. $\mathrm{Cu} / \mathrm{Cu}^{2+}$, i.e. positive from the UPD range, thus the surface is copper-free. Electrolyte: $50 \mathrm{mM} \mathrm{H}_{2} \mathrm{SO}_{4}+1 \mathrm{mM} \mathrm{CuSO}_{4}$ with the solvent being a $2: 1$ mixture of $\mathrm{HOCH}_{2} \mathrm{CH}_{2} \mathrm{OH}: \mathrm{H}_{2} \mathrm{O}$. Tunneling parameters: $\mathrm{I}=0.5 \mathrm{nA}, \mathrm{V}=120 \mathrm{mV}$. Image size: $138 \mathrm{~nm} \times 138 \mathrm{~nm}$. 
a)

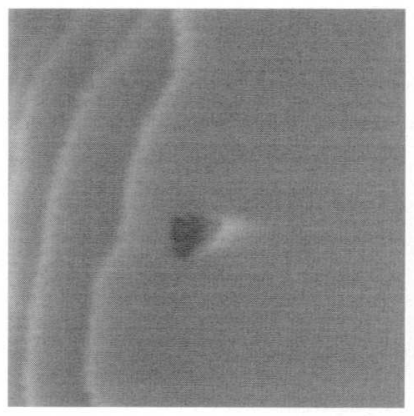

b)

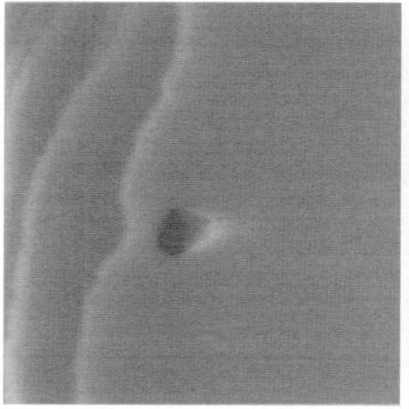

c)

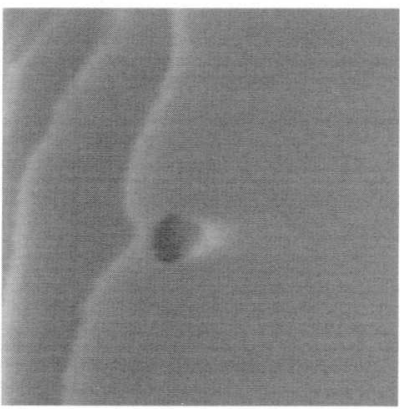

d)

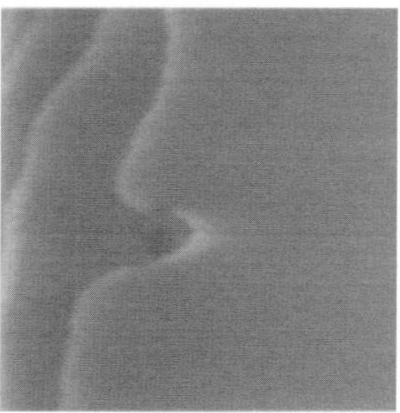

e)

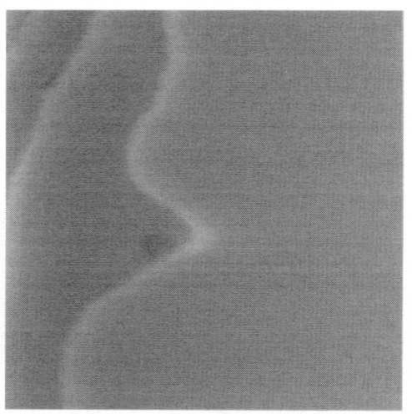

f)

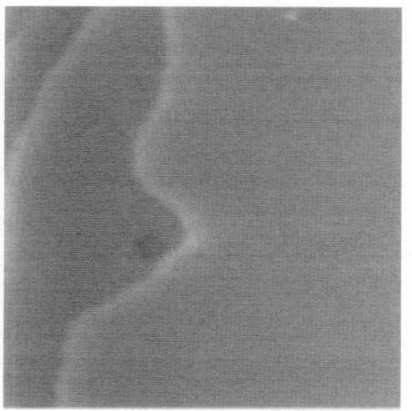

g)

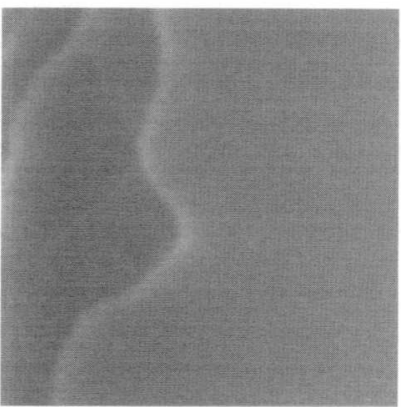

Fig. 7

Brought to you by | Universitaetsbibliothek Basel Authenticated 


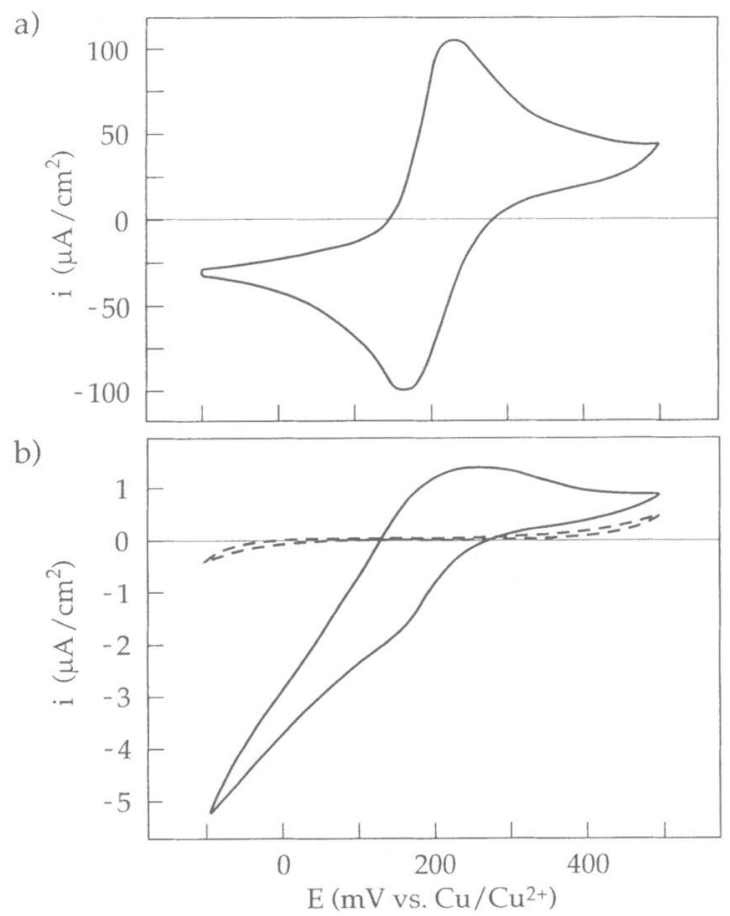

Fig. 8. Cyclic voltammograms for an $\mathrm{Au}(111)$ electrode at $300 \mathrm{~K}$ (a), for a $\mathrm{C}_{16}$ thiolatecovered $\mathrm{Au}(111)$ electrode at $300 \mathrm{~K}$ (b, dashed line) and at $335 \mathrm{~K}$ (b, solid line). Electrolyte: $1000 \mathrm{mM} \mathrm{KCl}+1 \mathrm{mM} \mathrm{K}_{3} \mathrm{Fe}(\mathrm{CN})_{6}$ with the solvent being a $2: 1$ mixture of $\mathbf{H O C H}_{2}$ $\mathrm{CH}_{2} \mathrm{OH}: \mathrm{H}_{2} \mathrm{O}$. Scan rate: $50 \mathrm{mV} / \mathrm{s}$. Potentials were measured vs. the $\mathrm{Ag} / \mathrm{AgCl}$ electrode and are reported vs. a hypothetical $\mathrm{Cu} / \mathrm{Cu}^{2+}(1 \mathrm{mM})$ reference electrode for an easier comparison with the previously shown voltammograms.

Extending the view from a single molecule to neighbouring molecules, we note that the coverage of sulphur atoms (and thus of the alkanethiolates) is in most cases $1 / 3$; the sulphur atoms occopy a $(\sqrt{3} \times \sqrt{3}) \mathrm{R} 30^{\circ}$ lattice (see above). Exceptions are encountered for the short-chain thiolates (e.g. $n=6$ where this lattice and a striped structure coexist) or for the low coverages attainable either for samples annealed above $370 \mathrm{~K}$ or by vacuum deposition of thiols. As we already pointed out in section 1, the $(\sqrt{3} \times \sqrt{3}) \mathrm{R} 30^{\circ}$ geometry is also found for the $\mathrm{S} / \mathrm{Au}(111)$ system. This and other (quasi)hexagonal structures (e.g. found when soft bases are adsorbed at noble metal surfaces; even when the substrate structure is not hexagonal $[1,2])$ are typical for a balance between adsorbate-substrate and adsorbateadsorbate interactions.

Clearly, this balance has to be additionally affected when alkyl chains interact with each other. It is well known that this results in the all-trans 


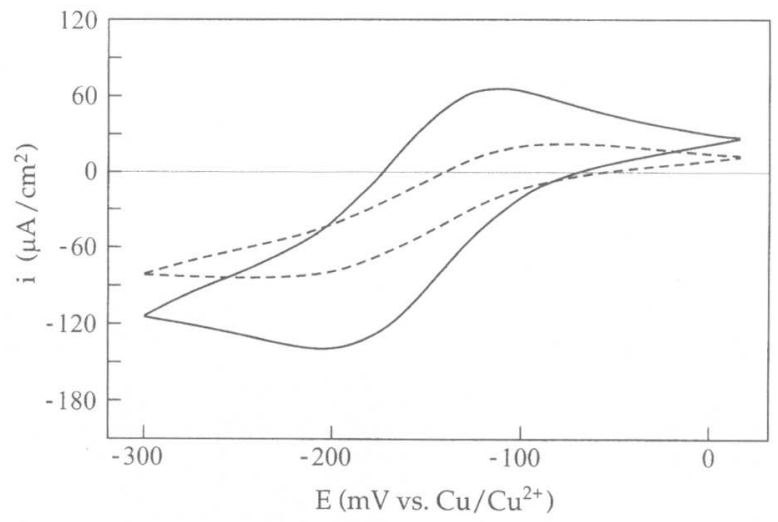

Fig. 9. Cyclic voltammograms for a $C_{10}$ thiolate (solid line) and a $C_{14}$ thiolate-covered (dashed line) $\mathrm{Au}(111)$ electrode at $300 \mathrm{~K}$. Electrolyte: $50 \mathrm{mM} \mathrm{H}_{2} \mathrm{SO}_{4}+1 \mathrm{mM}$ $\mathrm{Ru}\left(\mathrm{NH}_{3}\right)_{6} \mathrm{Cl}_{3}$. Scan rate: $50 \mathrm{mV} / \mathrm{s}$. Potentials were measured vs. the $\mathrm{Ag} / \mathrm{AgCl}$ electrode and are reported vs. a hypothetical $\mathrm{Cu} / \mathrm{Cu}^{2+}(1 \mathrm{mM})$ reference electrode for an easier comparison with the previously shown voltammograms.

a)
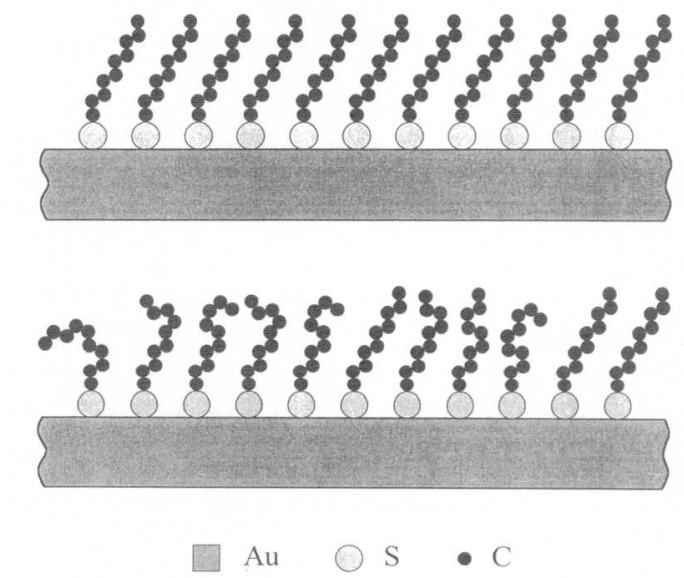

Fig. 10. Models of the $\mathrm{CH}_{3}\left(\mathrm{CH}_{2}\right)_{9} \mathrm{~S} / \mathrm{Au}(111)$ interface: (a) alkyl chains in the all-trans conformation, (b) alkyl chains partially in gauche conformation.

configured alkyl chains being tilted away from the surface normal by about $30^{\circ}$ (see Fig. 10(a)). The azimuthal tilt direction lies between the directions of the next and nearest next sulphur neighbours. The above-mentioned $c(4 \times 2)$ lattice appears to be based on an ordered distribution of alkyl chain twist angles (presumably a twist around the $\mathrm{S}-\mathrm{C}$ axes); structures based on ordered distributions of alkyl twist angles exist also in bulk alkanes [4]. 
We can conclude that the thiolate structure is based on the strong $\mathrm{Au}-\mathrm{S}$ bond; the maximum coverage is governed by $\mathrm{S}-\mathrm{S}$ and interchain interactions - each one exhibits an energy minimum, and their interdependence yields an overall minimum with the optimum geometry described above. The densely spaced alkyl chains form an effective spacer layer that blocks electron transfer as evidenced by the voltammetric data.

On the length scale of $10 \mathrm{~nm}$, we find the grooves that form the boundaries between differently oriented molecular domains. Unfortunately, it is impossible to deduce a structural model for them: firstly, the mechanism of tunnelling on thiolates is still under debate, hence the depth is difficult to interpret; secondly, molecular resolution of the grooves is very difficult. The simplest idea is an antiphase boundary where the $S-S$ interdomain distance is larger than the intradomain distance of $\sqrt{3}$ atomic gold distances, but also missing rows of thiolate molecules have been suggested [55].

Finally let us shortly focus on the mesoscopic scale $(\mu \mathrm{m})$ : this is the typical length of gold substrate steps. Very long and straight steps are presumably due to the healing of volume defects during the gold flame annealing (gliding along internal (111) planes); hence they can cross each other. Shorter and more round steps should develop via transport processes during gold flame annealing and quenching.

\subsection{Thermal dynamics}

Substantial changes of the surface morphology manifest themselves in step movements which can be ascribed to the diffusion of gold adatoms or single atom vacancies. Indeed we use the smoothening effect of surface diffusion in both the vacuum heating and flame annealing processing of our gold samples. Naturally, such processes are thermally activated. On thiolatecovered $\mathrm{Au}(111)$, their rate is much higher than on bare $\mathrm{Au}(111)$ since the $\mathrm{Au}-\mathrm{Au}$ interaction is weakened by the strong $\mathrm{Au}-\mathrm{S}$ bond. Substrate atom diffusion was also recorded for similarly strongly bound halogen atoms on $\mathrm{Au}(100)$ [69a], Au(111) [69b], Au(110] [70] and Pt(110) [71, 72]. High temperature dosing of halogenes can even produce virtually defect-free surfaces $[2,73]$ as can prolonged annealing of thiolate-covered $\mathrm{Au}(111)$ [42]. For this annealing procedure, the vacancies and step edges move by diffusion of single substrate atom vacancies $[26,45]$. This leads to Ostwald ripening before the vacancies reach each other (vacancy coalescence) and finally other steps (vacancy annihilation). We can group all such events under the heading 'strongly activated': the thermodynamic driving forces have to be so large that they result in desorption of more weakly bound adsorbates. An example for a driving force is the temperature that should be above ca. $800 \mathrm{~K}$ for gold flame annealing (acting to desorb impurities and resulting in large scale step movements) or above ca. $340 \mathrm{~K}$ for vacancy coalescence on $\mathrm{C}_{10}$ thiolate covered $\mathrm{Au}(111)$ [61]. 
Another example for 'strong activation' is the electrode potential; changing it to either more positive or more negative values can result in desorption of adsorbed substances and surface diffusion. In most cases, an electron is transferred from or to the adsorbate during the desorption. E.g. only below $-1100 \mathrm{mV}$ thiolates desorb from $\mathrm{Au}(111)$ [74, 75], demonstrating that they bind strongly; below $-500 \mathrm{mV}$ sulphide desorbs from $\mathrm{Au}(111)$ [7]; below $-300 \mathrm{mV}$ iodide desorbs from Pt(110), causing surface mass transport of the substrate [72]; $-200 \mathrm{mV}$ suffice to desorb the weaker bonded sulphate ion from platinum surfaces [76]). In the positive potential range, the situation can be much more complex; often an adsorbate is first oxidized and the product can desorb, e.g. alkanethiolates are oxidized to alkanesulphonic acids. In any cases, changing the potential will supply the $\mathrm{CH}_{3}\left(\mathrm{CH}_{2}\right)_{n-1} \mathrm{~S} / \mathrm{Au}(111)$ interface with additional electrons (or draw electrons from it) and thereby weaken the $\mathrm{Au}-\mathrm{Au}$ and $\mathrm{Au}-\mathrm{S}$ interactions. The first case leads to substrate mobility, the latter to adsorbate surface diffusion or desorption.

However, the analogy to halogenide or sulphide adlayers reaches its limits when we consider that in the course of surface diffusion not only $\mathrm{Au}-\mathrm{Au}, \mathrm{Au}-\mathrm{S}$ and $\mathrm{S}-\mathrm{S}$ interactions, but also interchain forces come into play. Clearly, for longer alkyl chains they are larger and present an additional barrier; hence the mobilities will be lowered (as observed [43]). Whether thiolate molecules remain bound to a moving gold adatom or not, during a diffusion event interchain van-der-Waals bonds are broken and reestablished. Thus the thiolate has to reorient which can entrain formation or destruction of the all-trans conformation and change of azimuth and twist angle.

At temperatures above ca. $330 \mathrm{~K}$, a large part of the thiolate molecules may exist in an energetically (slightly) disfavoured state such as distorted twist angles or gauche conformations; the sulphur atoms remain in a fixed position. Let us name such a situation 'moderately activated'. Locally the effective thickness will be lowered, i.e. 'spots' appear in the otherwise dense 'forest' of alkyl chains (see Fig. 10(b)). Such 'spots' are not to be confused with missing molecules (which are rare if the self-assembly was given sufficient time). Here an ion in the electrolyte can approach the gold surface much more closely. It can thereby at least partially penetrate the thiolate, facilitating an electron transfer to or from the gold surface. For this reason we detect higher double layer charging or redox currents when we increase the temperature. The currents also increase when we use shorter alkyl chains - in this case, the molecular spacer layer becomes thinner, and an ion can (even without penetration) approach the gold surface more closely than in the case of long chains (see Fig. 9). We note that 'moderately activated' processes cannot be brought about by potential changes - this means that we can vary the potential in a rather wide range (between 


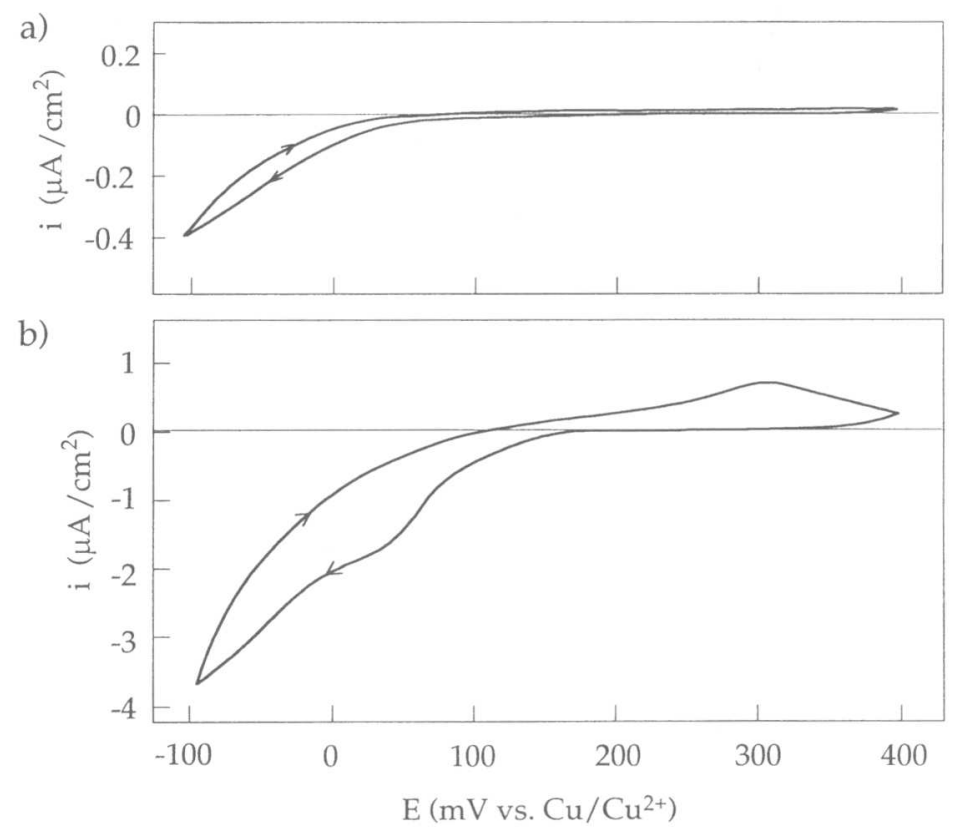

Fig. 11. Cyclic voltammograms for $C_{10}$ thiolate-covered $A u(111)$ at $300 \mathrm{~K}$ (a) and $335 \mathrm{~K}$ (b) showing the temperature dependent blocking behaviour towards copper deposition. Electrolyte: $50 \mathrm{mM} \mathrm{H}_{2} \mathrm{SO}_{4}+1 \mathrm{mM} \mathrm{CuSO}_{4}$ with the solvent being a 2:1 mixture of $\mathrm{HOCH}_{2} \mathrm{CH}_{2} \mathrm{OH}: \mathrm{H}_{2} \mathrm{O}$. Scan rate: $10 \mathrm{mV} / \mathrm{s}$.

$500 \mathrm{mV}$ and $-200 \mathrm{mV}$ ) without noticeable changes of surface properties. In other words, in this range the $\mathrm{CH}_{3}\left(\mathrm{CH}_{2}\right)_{n-1} \mathrm{~S} / \mathrm{Au}(111)$ system is ideally polarizable.

\section{Copper electrodeposition on alkanethiolate-covered $\mathrm{Au}(111)$}

\subsection{From UPD islands to OPD layers}

We begin the presentation of the copper deposition studies with the voltammetric experiments. Here voltammetry is not simply an analytic tool, but also the method to achieve potential control of the system (for the STM and XPS experiments, we started at a potential of $400 \mathrm{mV}$ where copper deposits neither on bare nor on thiolated gold, then lowered the potential in steps of 20,50 or $100 \mathrm{mV}$ ).

The voltammograms of thiolate-covered $\mathrm{Au}(111)$ samples in contact with $\mathrm{Cu}^{2+}$ in electrolytes based on water as well as on ethylene glycol/water are usually featureless with low double layer charging currents (see Fig. 11). 
In the UPD regime, i.e. above the $\mathrm{Cu} / \mathrm{Cu}^{2+}$ equilibrium potential of $0 \mathrm{mV}$, no features were found either, albeit in some cases very shallow peaks assigned to copper UPD showed up. This behaviour reflects a certain sampleto-sample variability of thiolate layers as also reported by other groups $[24,77]$. Below $0 \mathrm{mV}$ the current drops slightly, pointing towards copper deposition at a much reduced rate compared to a bare gold substrate where currents drop to several ten $\mu \mathrm{A} / \mathrm{cm}^{2}$ (compare e.g. the current transients for copper deposition on $\mathrm{Au}(111)$ [78, 79]). Rising the temperature increases the double layer current and reveals small UPD peaks for all samples (see Fig. 11). A reasonable explanation is the high temperature defect structure of the thiolate (see section 3.2) that should accelerate the reduction of $\mathrm{Cu}^{2+}$. Faradaic and charging currents also increase with decreasing thiolate chain length. These findings compare well with the behaviour in copper-free electrolytes (see section 3.1): higher temperatures and shorter alkyl chains generally increase the current, whether it is due to charging or Faradaic currents - in both cases electrons have to be transferred through the thiolate to the adjacent electrolyte phase.

After regulating the temperature and setting the potential to a fixed value, the surface structure can be followed time resolved by in situ STM. We now have to consider three parameters influencing the morphology: temperature, potential and thiolate chain length. In a certain range of the parameters (UPD for all thiolate chain lengths and temperatures; OPD only for $n>12$ at lower temperatures, see Table 1) the system showed a surprising topography: monolayer high ${ }^{1}$ islands with an average diameter of $2 \mathrm{~nm}$ cover 10 to $15 \%$ of the surface (Fig. 12). They are randomly distributed and also found in the substrate vacancies; they are not pinned at steps or at domain boundaries. The initial nucleation of these islands could not be followed. Further growth proceeded either not or extremely slowly at less than $0.7 \mathrm{~nm}$ in two hours. Apart from the fact that island formation in the UPD range is a rare phenomenon (but see [37] and [38]), the observed islands have the unique property of changing neither size nor shape for hours, i.e. they can truly be addressed as stable or at least metastable nanostructures.

At all other conditions (OPD for $n \leq 12$ and OPD for all $n$ at $345 \mathrm{~K}$ ) a pseudo-layer-by-layer growth was found (Fig. 13): islands grow until they coalesce. Only islands already nucleated in the UPD regime grow, no further islands nucleate. In electrochemical terms, the nucleation is instantaneous, not progressive, in contrast to copper deposition on bare $\mathrm{Au}(111)$ [79]. When a monolayer is almost filled, the next layer nucleates on top. However, the growth speed depends strongly on the temperature and the chain length. At $300 \mathrm{~K}$, even the shortest chain $(n=6)$ system exhibits a very slow growth (at least one hour per layer). At high temperatures, all thiolate layers allow a rapid growth in the range of minutes per layer.

1 The monolayer heights of $\mathrm{Au}(111)(0.236 \mathrm{~nm})$ and $\mathrm{Cu}(111)(0.208 \mathrm{~nm})$ are too similar to be distinguished in our STM setup. 
Table 1. Copper growth scenario as function of alkanethiolate chain length $n$, temperature and deposition potential range (OPD: $\angle 0 \mathrm{mV}$, UPD: $>0 \mathrm{mV}$ ).

\begin{tabular}{c|c|c} 
& short chain & long chain \\
\hline $\begin{array}{c}\text { room } \\
\text { temperature }\end{array}$ & UPD 2D islands & UPD 2D islands \\
OPD layer-by-layer & OPD 2D islands \\
\hline $\begin{array}{c}\text { elevated } \\
\text { temperature }\end{array}$ & UPD 2D islands & UPD 2D islands \\
OPD layer-by-layer & OPD layer-by-layer
\end{tabular}

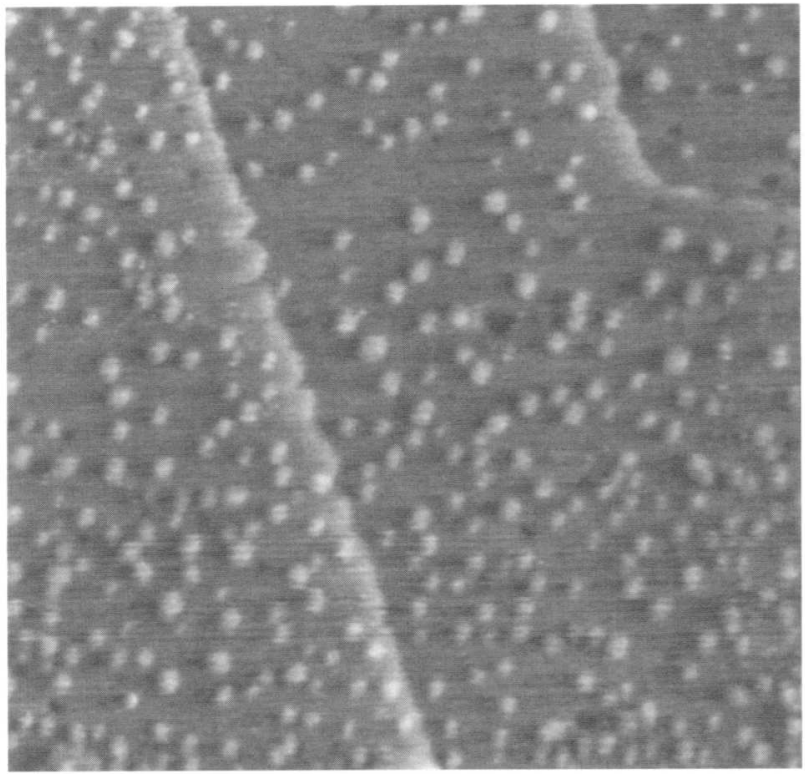

Fig. 12. In situ STM image showing the $2 \mathrm{D}$ copper island formation on a $\mathrm{C}_{1 \times}$ thiolatecovered $\mathrm{Au}(111)$ surface in the UPD range. Electrolyte: $50 \mathrm{mM} \mathrm{H}_{2} \mathrm{SO}_{4}+1 \mathrm{mM} \mathrm{CuSO}_{4}$. Electrode potential: $30 \mathrm{mV}$ vs. $\mathrm{Cu} / \mathrm{Cu}^{2}$. Tunneling parameters: $\mathrm{I}=0.3 \mathrm{nA}, \mathrm{V}=200 \mathrm{mV}$. Image size: $220 \mathrm{~nm}+220 \mathrm{~nm}$.

For a special set of the parameters (short chain thiolates, $300 \mathrm{~K}$, OPD) we observed a fractal shape of the growing and coalescing islands as visualized in Fig. 14: each island develops three 'arms' which can again branch off. The 'arms' form angles of $120^{\circ} \mathrm{C}$. corresponding to the sym- 


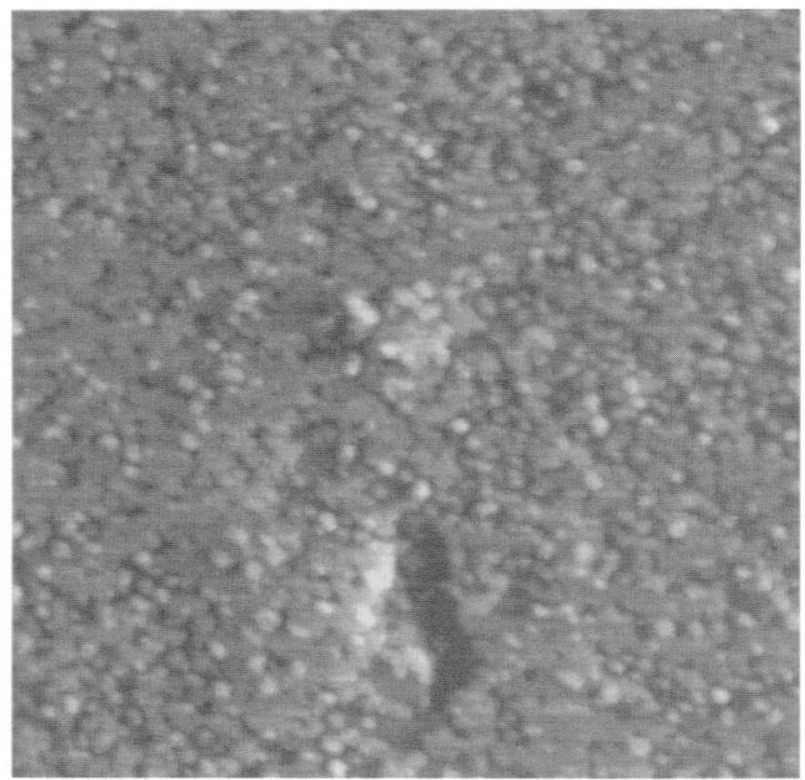

Fig. 13. In situ STM picture exemplifying the OPD copper layer-by-layer growth on a $\mathrm{C}_{10}$ thiolate-covered $\mathrm{Au}(111)$ electrode at $300 \mathrm{~K}$. Electrode potential: $-90 \mathrm{mV}$ vs. $\mathrm{Cu} /$ $\mathrm{Cu}^{2+}$. Electrolyte: $50 \mathrm{mM} \mathrm{H}_{2} \mathrm{SO}_{4}+1 \mathrm{mM} \mathrm{CuSO}_{+}$. Tunneling parameters: $\mathrm{I}=0.4 \mathrm{nA}$, $\mathrm{V}=110 \mathrm{mV}$. Image size: $220 \mathrm{~nm} \times 220 \mathrm{~nm}$.

metry of the underlying gold surface and/or to the symmetry of the sulphur adlattice. Such growth shapes are usually associated with a kinetically hindered growth [80].

To obtain information on the chemical composition of the interface, we emersed $\mathrm{C}_{18}$ thiolate samples on which copper had been deposited for $3 \mathrm{~h}$ at 50 or $20 \mathrm{mV}$ at $300 \mathrm{~K}$, i.e. samples covered by copper islands. They were investigated with XPS. The overview spectra (see Fig. 2, sample B) show the same features as in absence of copper, but additionally a Cu $2 \mathrm{p}_{3 / 2}$ emission is present (correspondingly the gold emission decreases). Intensity curves (Fig. 4) indicate a rapid destruction with X-ray exposure. The oxygen contamination is slightly higher than for the copper-free samples, but still corresponds only to a minor portion compared to that of copper. From the intensity ratio, the photoemission cross sections and the binding energy of $\mathrm{Cu} 2 \mathrm{p}_{3 / 2}(932.1 \mathrm{eV})$ we conclude that the deposited copper did not oxidize although the samples had to endure more than one minute of contact with laboratory air which should suffice for complete oxidation of a copper surface. Hence the copper is protected against oxidation. In addition to the gold and sulphur signals, the copper peak, too, was strongly suppressed at 


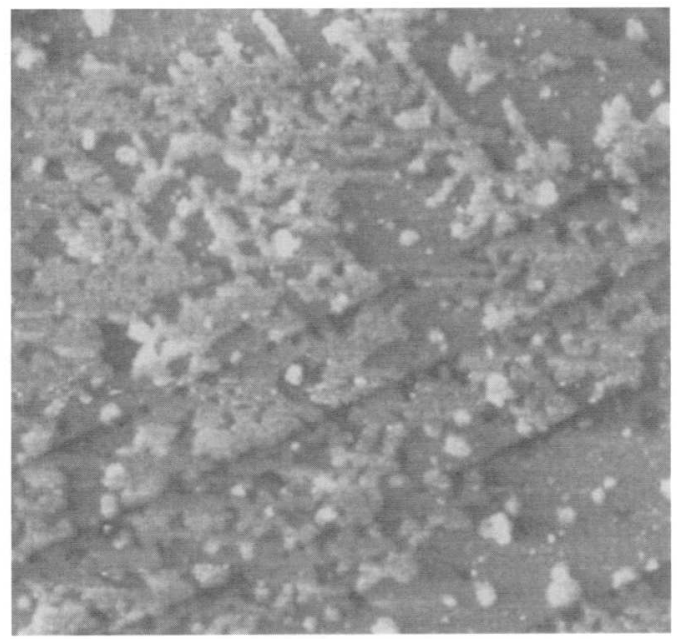

Fig. 14. In situ electrochemical STM image of fractal islands that nucleated during the growth of the first copper layer on a $C_{6}$ thiolate-covered $\mathrm{Au}(111)$ electrode at $300 \mathrm{~K}$. The image was obtained after $80 \mathrm{~min}$ of $\mathrm{OPD}$ polarization at $-110 \mathrm{mV}$ vs. $\mathrm{Cu} / \mathrm{Cu}^{2+}$. Electrolyte: $50 \mathrm{mM} \mathrm{H}_{2} \mathrm{SO}_{4}+1 \mathrm{mM} \mathrm{CuSO}_{4}$. Tunneling parameters: $\mathrm{I}=0.5 \mathrm{nA}, \mathrm{V}=120 \mathrm{mV}$. Image size: $175 \mathrm{~nm} \times 175 \mathrm{~nm}$.

grazing emission (see Fig. 3). This emphasizes that the copper penetrated the thiolate layer during the deposition.

\subsection{Structure of electrodeposited copper}

The formal electrode potential (measured here with the $\mathrm{Cu} / \mathrm{Cu}^{2+}$ reference electrode) we quote is not the one of the thiolate/electrolyte interface. Hence theoretically one cannot expect a copper bulk deposition at $0 \mathrm{mV}$ (even at highest $\mathrm{Cu}^{2+}$ concentrations). However, the potential drop in the thiolate layers should not exceed $100 \mathrm{mV}$ since the overpotential for copper bulk deposition of about $150 \mathrm{mV}$ is the same as on bare $\mathrm{Au}(111)$ and $\mathrm{Au}(100)$ [18]. The reduction of $\mathrm{Cu}^{2+}$ in acidic media produces copper metal. In our case it grows in islands, and the first question we have to pose concerns the copper islands' distance from the gold surface. We already disproved the idea of copper residing in thiolate-free surface areas [29] since such areas would result in clear $\mathrm{Cu} / \mathrm{Au}(111) \mathrm{UPD}$ peaks for all samples.

Fig. 15 illustrates the two further principal possibilities that arise: first, the copper islands could be located between thiolate and gold $\left(\mathrm{CH}_{3}\left(\mathrm{CH}_{2}\right)_{n-1} \mathrm{~S} / \mathrm{Cu} / \mathrm{Au}(111)\right)$, second, they could be on top of the thiolate layer $\left(\mathrm{Cu} / \mathrm{CH}_{3}\left(\mathrm{CH}_{2}\right)_{n-1} \mathrm{~S} / \mathrm{Au}(111)\right)$. We here discard other models because they are either pure speculation (e.g. copper between alkyl chains) or un- 
a)
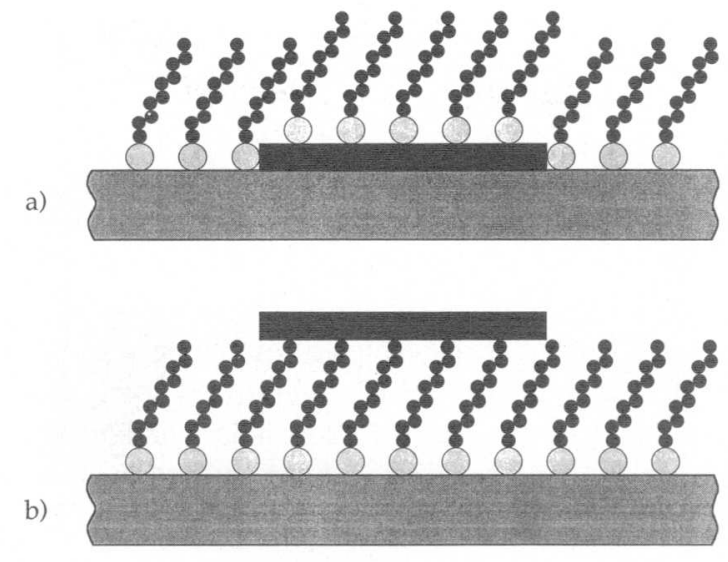

$\square \mathrm{Au} \quad \mathrm{Cu} \bigcirc \mathrm{S} \cdot \mathrm{C}$

Fig. 15. Schematic representation of the possible structures of the $\mathrm{Cu} /$ thiolate/gold interface: copper electrocrystallized below (a) and above (b) the thiolate layer.

likely (e.g. alloying into the gold surface that is only known for the (110) face [81]). The second model would postulate isolated copper islands connected to the methyl end groups (see Fig. 15(b)). As we already pointed out [27], one might think that the necessary electron transfer to the top of the chains should nicely explain the slow formation (but see section 4.4!). However, several arguments speak against the model: if one observes UPD, the growing metal should have a stronger interaction with the substrate than with itself. For copper on top of the thiolate layer, this is impossible because the $\mathrm{Cu}-\mathrm{H}$ (or $\mathrm{Cu}-\mathrm{CH}_{3}$ ) interaction is very weak. The islands even withstand rinsing with water, i.e. they are strongly bound. Also, heating involving the formation of alkyl gauche defects should shorten some (but not all!) of the thiolate chains below an island. Then the island that behaves as a rigid copper layer 'disk' (compared to the thiolate layer) would remain attached only to the intact thiolates, but the distance to the gold surface would be the same as at low temperature (when all molecules are intact). Hence the electron transfer probability would be the same at low and high temperatures, and copper should deposit at the same rate; this is not observed.

Furthermore, let us assume an island that additionally has some contact to the substrate (i.e. a copper column through the thiolate). Such an island of copper atoms should, in absence of strongly bound coadsorbates $\left(\mathrm{SO}_{4}^{2-}\right.$ does not qualify!), continue to grow 3D [22] as $\mathrm{Cu} / \mathrm{Au}(111)$, in contrast to the observations. Clearly, if the thiolate layer is damaged by large negative potential excursions, 3D nodules do indeed develop [24, 25]. 
Copper placed below the thiolate (Fig. 15(a)) is in accordance with the following facts: firstly, the XPS data show an angular dependence of the $\mathrm{Cu} 2 \mathrm{p}$ emission which must be due to considerable amounts of material, i.e. thiolate molecules, on top of the copper. Secondly, the resulting $\mathrm{Cu}-\mathrm{S}$ bond is strong and can easily explain the passivation of copper [29]: it is impossible to rinse off the islands, they withstand very positive potentials, copper does not react with air which would produce higher O 1s XPS signals. Note that such a thiolate/copper structure can be called a coadsorption structure, and examples like $\mathrm{V} / \mathrm{Ag} / \mathrm{Pt}(111)$, detected after electrodeposition of silver on $\mathrm{I} / \mathrm{Pt}(111)$ (not adsorption of iodide on $\mathrm{Ag} / \mathrm{Pt}(111)$ !) are well documented $[33,34,73]$. The question we have to address is whether copper atoms can penetrate a thiolate layer; in section 4.4 we will show that this is indeed possible. Here we mention that silver evaporated on thiolate/Au(111) in vacuum has indeed been observed to penetrate the layer $[11,82]$. Let us also mention that thiolates readily adsorb on $\mathrm{Cu}(100)$ [83] and that even multilayer copper thiolates can form [84]. All these arguments lead us to propose a $\mathrm{CH}_{3}\left(\mathrm{CH}_{2}\right)_{n-1} \mathrm{~S} / \mathrm{Cu} / \mathrm{Au}(111)$ structure.

Further structural details are much more difficult to observe. This concerns the lattice of the copper atoms which could be $(1 \times 1)$ as in a complete UPD layer $[15,85,86]$, a honeycomb $(\sqrt{3} \times \sqrt{3}) \mathrm{R} 30^{\circ}$ lattice as in the incomplete $\mathrm{Cu}+\mathrm{SO}_{4}^{2-}$ coadsorption UPD layer on $\mathrm{Au}(111)$ [14, 86-88] or a normal $(\sqrt{3} \times \sqrt{3}) \mathrm{R} 30^{\circ}$ structure. All three would offer reasonable adsorption places (e.g. hollow sites) for the sulphur atoms. A more intricate feature is the structure of the islands' rims. Here one could probably find a topography that is distinctly different from that in the island - thus one may explain the surprising stop of growth and hence the instantaneous instead of progressive nucleation. Since this is only the case for long thiolate chains and low temperatures, we can speculate that especially the alkyl chains adjust themselves in a special structure. However, STM observations (which for the currents we employed probe the sulphur atoms rather than the chains) did not yield any clues.

\subsection{Thermal behaviour}

For an interpretation of temperature phenomena we have to consider the changes that develop in the thiolate layer during annealing. The gradual development of thiolate defect structures such as gauche conformations, new twist angles or possibly azimuthal disorder (see section 3.2 ) will again allow for increasing penetration of ions ${ }^{2}$, this time including $\mathrm{Cu}^{2+}$. As for $\mathrm{Fe}(\mathrm{CN})_{6}^{3-}$, a reduction will occur much faster. Doubtlessly, the complete penetration is now even more facile. However, we also have to explain a qualitative change: islands grown on thiolates of all chain lengths can co-

${ }^{2}$ On the fate of the hydration shell we can only speculate. This is even true in absence of thiolate [89]! 
alesce at high temperatures. This means that the unknown barrier against further growth (presumably at the island rim) is overcome by thermal activation. The pseudo-layer-by-layer growth is due to the presence of the thiolate which always stays on top; otherwise the growth (on pure copper) would carry on much faster and 3D nodules would result. This is the classical picture of a surfactant that hinders the growth in the direction normal to the surface as also observed when copper was deposited on gold in presence of crystal violet [20]. However, our surfactant is adsorbed in a well-characterized geometry and will neither desorb nor readsorb during deposition. Thus we exclude one of the many processes that complicate the understanding of surfactant action in electrodeposition.

At high temperatures substrate steps become mobile ('strong activation', see section 3.2). When we accept that copper is bound to the substrate (see section 4.2), copper island rims - copper step edges - should be at least as mobile as the substrate steps. This is equivalent to an incrased island perimeter mobility, i.e. the fractal island shapes transform to compact shapes. Obviously, the barrier against further growth that prevails at low temperature is overcome, and further growth and coalescence can occur. This arguments are in line with the theory of surface diffusion limited aggregation that has successfully been applied to explain ramified metal islands grown in vacuum. However, the fact that temperature also enhances copper penetration and thus deposition rate makes a quantitative theoretical modelling very difficult, since two interdependent barriers (thiolate penetration and the barrier at the island rim) are overcome at the same time.

\subsection{Potential dynamics - copper deposition rates}

We shall start the discussion with a look at the permittable limits of the potential. At the positive end, we dissolve the copper islands at potentials several hundred $\mathrm{mV}$ positive of the $\mathrm{Cu} / \mathrm{Cu}^{2+}$ equilibrium value. Note that we have to wait several hours at $400 \mathrm{mV}(300 \mathrm{~K})$, and some islands resist dissolution even at $1000 \mathrm{mV} \mathrm{[29]} \mathrm{which} \mathrm{impressively} \mathrm{demonstrates} \mathrm{the} \mathrm{pas-}$ sivation. As one expects, the dissolution is much faster when the temperature is raised.

In the cathodic regime, only well below $-200 \mathrm{mV}$ the layer growth can change to 3D deposition of nodules with diameters above $100 \mathrm{~nm}$. Since voltammograms show copper UPD peaks after such negative excursions, some bare substrate spots appear to exist which would clearly cause the observed growth of large nodules.

For the UPD processes, no current flow is found since the growth is so slow that the resulting peaks would be far too shallow (sub-nA range). In the OPD range, the detected currents usually predict a deposition of a monolayer of copper during several minutes which is - at $300 \mathrm{~K}$ - far more 
than observed by STM. The discrepancy can be explained by the destruction of the sample close to the viton ring where we occasionally found visible copper deposits; this means that copper had here deposited at least 100 times thicker than elsewhere. Thus the global current is unreliable at least when its value is small. Therefore we estimate the deposition rate from STM measurements: typical rates are $10 \%$ of a monolayer in one to two hours (UPD), one layer in two hours for copper layer growth on short and medium chain thiolates (OPD) and one layer per minute at high temperatures $(\mathrm{OPD})^{3}$. Assuming a $\mathrm{Cu}(1 \times 1)$ geometry on $\mathrm{Au}(111)$ with a monolayer charge of $440 \mu \mathrm{C} / \mathrm{cm}^{2}$, this gives rates of $0.01 \mu \mathrm{A} / \mathrm{cm}^{2}, 0.06 \mu \mathrm{A} / \mathrm{cm}^{2}$ and $7 \mu \mathrm{A} / \mathrm{cm}^{2}$, respectively. We can set limits to the experimental rates:

$$
0.005 \mu \mathrm{A} / \mathrm{cm}^{2}<r<10 \mu \mathrm{A} / \mathrm{cm}^{2} \text {. }
$$

In order to exclude or verify possible mechanisms, it is instructive to compare those rates to rates calculated under typical conditions. Let us first assume that bulk diffusion of $\mathrm{Cu}^{2+}$ is the rate-limiting (slowest) process. Then the Cotrell equation would apply [12]:

$$
r_{1}=2 F c_{0} \sqrt{D / \pi t} \cdot[1-\exp (2 F \Delta E / R T)]
$$

where $F=96485 \mathrm{C} / \mathrm{mol}, D$ is the diffusion constant of $\mathrm{Cu}^{2+}$ in electrolyte $\left(5.7 \cdot 10^{-6} \mathrm{~cm}^{2} / \mathrm{s}[90]\right), c_{0}$ the $\mathrm{Cu}^{2+}$ concentration $(1 \mathrm{mM}), t$ the time, $R=8.314 \mathrm{~J} /(\mathrm{mol} \cdot \mathrm{K}), \Delta E$ the potential step causing the deposition (e.g. $-100 \mathrm{mV}$ ) and $T$ the temperature. We should then find

$$
r_{1} \approx 260 \mu \mathrm{A} / \mathrm{cm}^{2} \cdot \sqrt{1 /(t / \mathrm{s})}
$$

(comparison: $440 \mu \mathrm{A} / \mathrm{cm}^{2}$ accounts for a $\mathrm{Cu}(1 \times 1)$ monolayer on $\mathrm{Au}(111)$ deposited in one second) which is about 100 times larger than the transient we observed during the first minute of polarisation. This means that the diffusion is not the limiting factor.

This could leave the electron transfer as the slowest process. First let us concentrate on the case of copper deposition on copper, e.g. copper islands. Then the slowest possible rate is that at zero overpotential where dissolution and deposition currents cancel each other. Their value, the exchange current density, is [91]

$$
r_{2} \approx 500 \mu \mathrm{A} / \mathrm{cm}^{2}
$$

${ }^{3}$ The estimates are rough, hence the copper atom density in the islands (see section 4.2) plays no role. 
which is again too high. But of course the electron transfer which in fact makes up the exchange current density, is slowed down since the electrons have to pass through the thiolate layer. Using an electron tunnelling rate $k(n)$ we can write

$$
r_{3}=\sigma \cdot \theta \cdot k(n)
$$

where $\sigma=440 \mu \mathrm{A} / \mathrm{cm}^{2}$ is the above-mentioned charge for a copper monolayer, $\theta \approx 10 \%$ is the copper island coverage and $n$ the thiolate chain length. The ions to be reduced to result in the copper islands are supposed to be already at the interface. We could now try to calculate $k(n)$ through thiolates with data extracted from the redox couple voltammograms; however, they are limited by diffusion of the redox ions. Let us rather examine rates calculated from redox couples that are used as thiolate end groups and hence have a well-characterised distance from the gold surface [92-94]. Smalley et al. [94] found that the rates depend very strongly on $n$. The rates are $k(18)=0.2 \mathrm{~s}^{-1}, k(16)=1.4 \mathrm{~s}^{-1}$ and $k(10)=3300 \mathrm{~s}^{-1}$ giving

$$
\begin{aligned}
& r_{3}(n=18)=8.8 \mu \mathrm{A} / \mathrm{cm}^{2} \\
& r_{3}(n=16)=62 \mu \mathrm{A} / \mathrm{cm}^{2} \\
& r_{3}(n=10)=1.5 \cdot 10^{5} \mu \mathrm{A} / \mathrm{cm}^{2} .
\end{aligned}
$$

Once again, even these rates are too fast. Keeping in mind that we are presenting only rough estimates, one may at first glance concede that electron tunnelling could be the limiting factor for $n=18$ at high temperatures $\left(r \approx 7 \mu \mathrm{A} / \mathrm{cm}^{2}\right.$, see above). On the other hand, we already discussed that redox processes in our case (unmodified thiolates) are usually accompanied by a certain amount of penetration of the ion which would reduce the tunnelling distance and hence even accelerate the rates!

Concentrating on the described kinetics, we have to conclude that all discussed mechanisms are too fast. (We note that already a simple observation can hint at this: if we compare bare and thiolated $\mathrm{Au}(111)$ and assume similar diffusion constants and exchange currents for copper electrodeposition and $\mathrm{Fe}(\mathrm{CN})_{6}^{3 / 4-}$, the presence of thiolate reduces the copper deposition currents by a much larger factor, from tens of $\mu \mathrm{A} / \mathrm{cm}^{2}$ to $<1 \mu \mathrm{A} /$ $\mathrm{cm}^{2}$, than it reduces the reduction currents of the redox pair, from tens of $\mu \mathrm{A} / \mathrm{cm}^{2}$ to several $\mu \mathrm{A} / \mathrm{cm}^{2}$, see Fig. 8.) This suggests that copper ion or atom penetration into the thiolate layer is the rate-determining step. As the experiments show, penetration is facilitated by high temperatures which indeed substantially enhance the rate. Gauche defects and twisted S-C and $\mathrm{C}-\mathrm{C}$ bonds as well as a possible azimuthal disorder make the layer more permeable, they 'make way' for the copper ions or atoms. This thermal activation of penetration is well known for metals which are evaporated on thiolate layers in vacuum $[46,82]$. 
Metal electrodeposition can usually be treated thermodynamically since the exchange process between metal ions and metal bulk sets up equilibrium conditions. Note that in our case the exchange is interrupted by the thiolate which brings pure kinetics into play. In this way, the process becomes better comparable with metal deposition phenomena in vacuum which are almost always kinetically hindered. Although it is not clear whether diffusion limited aggregation is at work (copper would then undergo surface diffusion underneath the thiolate or a copper thiolate would diffuse), the ramified shape of the islands is common for both environments.

\section{Conclusions}

Alkanethiolates assemble in densely packed, ordered monolayers on $\mathrm{Au}(111)$. The order is determined by a subtle balance between $\mathrm{Au}-\mathrm{S}$, $\mathrm{S}-\mathrm{S}$ and interchain forces. With increasing temperature, the mesoscopic order (the size of domains with differently oriented thiolate molecules) increases. In contrast, in a single molecule, disorder progresses from the methyl groups over the chains and finally even the substrate becomes mobile. At the same time, the developing defects allow for better penetration of ions and electron transfer through thiolates.

Copper grows in nanometer-sized islands or pseudo-layer-by-layer on thiolate-precovered $\mathrm{Au}(111)$. If the potential window is constrained between $-200 \mathrm{mV}$ and $500 \mathrm{mV}$ vs. $\mathrm{Cu} / \mathrm{Cu}^{2+}$, the thiolate is not damaged. The most likely adsorption place of the copper is between substrate and sulphur as suggested by normal and grazing incident angle X-ray photoelectron spectroscopy (XPS). Three parameters, the thiolate chain length, the deposition potential and the temperature control the copper shape and the deposition kinetics (see Table 1). A third shape, 3D copper nodules, develops below $-200 \mathrm{mV}$ when the thiolate is damaged.

In detail, in situ Scanning Tunnelling Microscopy (STM) shows that the copper islands grow faster for shorter thiolate chains or higher temperatures. At $345 \mathrm{~K}$ an overpotential (OPD, potential $<0 \mathrm{mV}$ ) results for all thiolate chain lengths in a two-dimensional, pseudo-layer-by-layer growth. Copper islands nucleate and grow whilst no new nuclei form, and they coalesce almost completely before the next layer nucleates.

We showed that the copper growth proceeds extremely slowly and far from the electrochemical equilibrium. Hence the usual thermodynamical discussion is not applicable. As for most cases of vacuum deposition, kinetic limitations prevail, probably due to penetration of the thiolate: X-ray photoemission spectroscopy (XPS) of emersed samples showed that copper resides below the thiolate layer. The thus enforced slow growth can lead to the nanometer-sized islands and their ramified shape. It remains to elucidate whether this is only typical for thiolate layers, or whether it is a more 
general phenomenon operating whenever sufficiently thick or insulating layers are formed. Since many organic molecules, like surfactant additives, brighteners or corrosion inhibitors form such layers as can be studied by STM [20,95-97], it is possible that electrodeposition under the domination of the exchange process (thermodynamical) is a rather special phenomenon while in presence of adsorbates (e.g. in electroplating baths) kinetics would prevail.

The preadsorbed thiolate acts as a copper growth surfactant. The latter is normally added to the electrolyte; however, the surfactant action in our case is easier to interpret since a thiolate layer remains adsorbed during copper growth (its surface concentration does not change). Thus processes such as coadsorption or formation of metal ion-surfactant complexes are not operative here, and we can observe a pure surfactant action, up to now only followed by vacuum STM (see e.g. [98]).

\section{Acknowledgments}

We thank S. E. Gilbert for helpful discussions. AMB would like to thank the Alexander von Humboldt-Stiftung for a Feodor-Lynen-Stipendium. OC wants to express her gratitude to the Fondation pour des Bourses d'Études Italo Suisses (Lausanne) for a grant.

\section{References}

1. H. Baltruschat, U. Bringemeier and R. Vogel, Faraday Discuss. 94 (1992) 317.

2. A. M. Bittner, J. Wintterlin, B. Beran and G. Ertl, Surf. Sci. 335 (1995) 291.

3. W. Haiß, J. K. Sass, X. Gao and M. J. Weaver, Surf. Sci. 274 (1992) L 593.

4. O. M. Magnussen, B. M. Ocko, R. R. Adzic and J. X. Wang, Phys. Rev. B 74 (1995) 5510.

5. A. Wieckowski, B. C. Schardt, S. D. Rosasco, J. L. Stickney and A. T. Hubbard, Surf. Sci. 146 (1984) 115.

6. A. T. Hubbard, E. Y. Cao and D. A. Stern, in I. Rubinstein (Ed.), Physical Electrochemistry, Dekker, New York (1995) p. 469.

7. X. Gao, Y. Zhang and M. J. Weaver, J. Phys. Chem. 96 (1992) 4156.

8. R. G. Nuzzo, B. R. Zegarski and H. Dubois, J. Am. Chem. Soc. 109 (1987) 733.

9. M. A. Bryant and J. E. Pemberton, J. Am. Chem. Soc. 113 (1991) 8284.

10. N. Camillone, Ch. E. D. Chidsey, G.-Y. Liu and G. Scoles, J. Chem. Phys. 98 (1993) 3503.

11. D. R. Jung and A. W. Czanderna, Crit. Rev. Solid State Mater. Sci. 19 (1994) 1.

12. a) D. M. Kolb, M. Przasnyski and H. Gerischer, J. Electroanal. Chem. 54 (1974) 25.

12. b) E. Budevski, G. Staikov and W. J. Lorenz, Electrochemical Phase Formation and Growth, VCH, Weinheim (1996).

13. M. P. Green and K. J. Hanson, J. Vac. Sci. Technol. A 10 (1992) 3012.

14. T. Hachiya, H. Honbo and K. Itaya, J. Electroanal. Chem. 315 (1991) 275.

15. N. Ikemiya, S. Niyaoka and S. Hara, Surf. Sci. 311 (1994) L 641.

16. O. M. Magnussen, J. Hotlos, R. J. Nichols, D. M. Kolb and R. J. Behm, Phys. Rev. Lett. 64 (1990) 2929. 
17. N. M. Markovic and P. N. Ross, Langmuir 9 (1993) 580.

18. N. Batina, R. Will and D. M. Kolb, Faraday Discuss. 94 (1992) 93.

19. a) A. M. Bittner, J. Wintterlin and G. Ertl, Surf. Sci. 376 (1997) 267.

19. b) M. Dietterle, T. Will and D. M. Kolb, Surf. Sci. 342 (1995) 29.

20. W. Haiß, D. Lackey, J. K. Sass, H. Meyer and R. J. Nichols, Chem. Phys. Lett. 200 (1992) 343.

21. R. J. Nichols, D. M. Kolb and R. J. Behm, J. Electroanal. Chem. 313 (1991) 109.

22. R. J. Nichols, W. Beckmann, H. Meyer, N. Batina and D. M. Kolb, J. Electroanal. Chem. 330 (1992) 381.

23. W. U. Schmidt and R. C. Alkire, J. Electrochem. Soc. 141 (1994) L 85.

24. J. A. M. Sondag-Huethorst and L. G. J. Fokkink, Langmuir 11 (1995) 4823.

25. E. D. Eliadis, R. G. Nuzzo, A. A. Gewirth and R. C. Alkire, J. Electrochem. Soc. 114 (1997) 96.

26. O. Cavalleri, S. Gilbert and K. Kern, Surf. Sci. 377-379 (1997) 931.

27. O. Cavalleri, S. Gilbert and K. Kern, Chem. Phys. Lett. 269 (1997) 479.

28. O. Cavalleri, A. M. Bittner, H. Kind and K. Kern, Langmuir (1998), submitted.

29. S. Gilbert, O. Cavalleri and K. Kern, J. Phys. Chem. 100 (1996) 12123.

30. T. Hachiya and K. Itaya, Ultramicroscopy 42-44 (1992) 445.

31. N. Kimizuka and K. Itaya, Disc. Faraday Soc. 94 (1992) 117.

32. K. Ogaki and K. Itaya, Electrochim. Acta 40 (1995) 1249.

33. J. L. Stickney, S. D. Rosasco, D. Song, M. P. Soriaga and A. T. Hubbard, Surf. Sci. 130 (1983) 326.

34. A. T. Hubbard, J. Electroanal. Chem. 150 (1983) 165.

35. H. Matsumoto, J. Inukai and M. Ito, J. Electroanal. Chem. 379 (1994) 223.

36. G. M. Bommarito, D. Acevedo, F. Rodriguez and H. D. Abruna, J. Electroanal. Chem. 379 (1994) 135.

37. A. M. Bittner, J. Electroanal. Chem. 431 (1997) 51.

38. U. Schmidt, S. Vinzelberg and G. Staikov, Surf. Sci. 348 (1996) 261.

39. R. G. Nuzzo, E. M. Korenic and L. H. Dubois, J. Chem. Phys. 93 (1990) 767.

40. A. Badia, L. Cuccia, L. Demers, F. G. Morin and R. B. Lennox, J. Am. Chem. Soc. 119 (1997) 2682.

41. Y. Kim, H. L. Strauss and R. G. Snyder, J. Phys. Chem. 93 (1989) 7520.

42. J. P. Bucher, L. Santesson and K. Kern, Langmuir 10 (1994) 979.

43. O. Cavalleri, A. Hirstein and K. Kern, Surf. Sci. 340 (1995) L960.

44. R. L. McCarley, R. J. Dunaway and R. J. Willicut, Langmuir 9 (1993) 2775.

45. G. E. Poirier and M. J. Tarlov, J. Phys. Chem. 99 (1995) 10966.

46. A. W. Czanderna, D. E. King and D. Spaulding, J. Vac. Sci. Technol. A 9 (1991) 2607.

47. C. D. Bain, E. B. Troughton, Y.-T. Tao, J. Evall, G. W. Whitesides and R. G. Nuzzo, J. Am. Chem. Soc. 111 (1989) 321.

48. G. Beamson and D. Briggs, High Resolution XPS of Organic Polymers, Wiley, Chichester (1992).

49. B. Jäger, H. Schürmann, H. U. Müller, H.-J. Himmel, M. Neumann, M. Grunze and Ch. Wöll, Z. Phys. Chem. 202 (1997) 263.

50. P. Fenter, A. Eberhardt and P. Eisenberger, Science 266 (1994) 1216.

51. F. Reuse, personal communication, 1996.

52. J. P. Bucher, L. Santesson and K. Kern, Appl. Phys. A 59 (1994) 135.

53. D. Anselmetti, A. Baratoff, H.-J. Güntherodt, E. Delamarche, B. Michel, Ch. Gerber, H. Kang, H. Wolf and H. Ringsdorf, Europhys. Lett. 27 (1994) 365.

54. G. E. Poirier and M. J. Tarlov, Langmuir 10 (1994) 2853.

55. C. Schönenberger, J. Jorritsma, J. A. M. Sondag-Huethorst and L. G. J. Fokkink, J. Phys. Chem. 99 (1995) 3259. 
56. N. Camillone, T. Y. B. Leung, P. Schwartz, P. Eisenberger and G. Scoles, Langmuir 12 (1996) 2737.

57. N. Camillone, P. Eisenberger, T. Y. B. Leung, P. Schwartz, G. Scoles, G. E. Poirier and M. J. Tarlov, J. Chem. Phys. 101 (1994) 11031.

58. O. Cavalleri, PhD thesis, EPF, Lausanne (Switzerland) 1997.

59. G. E. Poirier, M. J. Tarlov and H. E. Rushmeier, Langmuir 10 (1994) 3383.

60. H.-J. Himmel, Ch. Wöll, R. Gerlach, G. Polansky and H.-G. Rubahn, Langmuir 13 (1997) 602.

61. O. Cavalleri, A. Hirstein, J. P. Bucher and K. Kern, Thin Solid Films 284-285 (1996) 392.

62. J. A. M. Sondag-Huethorst, C. Schönenberger and L. G. J. Fokkink, J. Chem. Phys. 98 (1994) 6826.

63. K. Edinger, A. Gölzhäuser, K. Demota, Ch. Wöll and M. Grunze, Langmuir 9 (1993) 4.

64. M. H. Dishner, J. C. Hemminger and F. J. Feher, Langmuir 13 (1997) 2318.

65. G. E. Poirier, Langmuir 13 (1997) 2019.

66. C. Schönenberger, J. A. M. Sondag-Huethorst, J. Jorritsma and L. G. J. Fokkink, Langmuir 10 (1994) 611.

67. Ch. A. McDermott, M. T. McDermott, J.-B. Green and M. D. Porter, J. Phys. Chem. 99 (1995) 13257.

68. A. Badia, R. Back and R. B. Lennox, Angew. Chem. Int. Ed. Engl. 33 (1994) 2332.

69. a) L. B. Goetting, B. M. Huang, T. E. Lister and J. L. Stickney, Electrochim. Acta 40 (1995) 143.

69. b) W. Haiß, PhD thesis, Technische Universität Berlin (1994).

70. X. Gao and M. J. Weaver, Phys. Rev. Lett. 73 (1994) 846.

71. P. Sandl, PhD thesis, Universität Bayreuth (1993).

72. A. M. Bittner, J. Wintterlin and G. Ertl, J. Electroanal. Chem. 388 (1995) 225.

73. D. Zurawski, L. Rice, M. Hourani and A. Wieckowski, J. Electroanal. Chem. 230 (1987) 221.

74. D.-F. Yang, C. P. Wilde and M. Morin, Langmuir 13 (1997) 243.

75. C. A. Widrig, C. Chung and M. D. Porter, J. Electroanal. Chem. 310 (1991) 335.

76. Y.-E. Sung, A. Thomas, M. Gambou-Aldeco, K. Franaszcuk and A. Wieckowski, J. Electroanal. Chem. 378 (1994) 131.

77. N. Camillone, T. Y. B. Leung and G. Scoles, Surf. Sci. 373 (1997) 333.

78. M. H. Hölzle and D. M. Kolb, Ber. Bunsenges. Phys. Chem. 98 (1994) 330.

79. M. H. Hölzle, V. Zwing and D. M. Kolb, Electrochim. Acta 40 (1995) 1237.

80. H. Brune, C. Romainczyk, H. Röder and K. Kern, Nature 369 (1994) 469.

81. F. Möller, O. M. Magnussen and R. J. Behm, Electrochim. Acta 40 (1995) 1259.

82. M. J. Tarlov, Langmuir 8 (1992) 80.

83. J. Scherer, M. R. Vogt, O. M. Magnussen and R. J. Behm, Langmuir 13 (1997) 7045.

84. H. Keller, P. Simak, W. Schrepp and J. Dembowski, Thin Solid Films 244 (1994) 799.

85. M. H. Hölzle, U. Retter and D. M. Kolb, J. Electroanal. Chem. 371 (1994) 101.

86. W. Haiß, J. K. Sass, D. Lackey and M. van Heel, in S. H. Cohen et al. (Ed.), Atomic Force Microscopy/Scanning Tunneling Microscopy, Plenum Press, New York (1994) p. 423 .

87. G. L. Borges, K. K. Kanazawa, J. G. Gordon, K. Ashley and J. Richer, J. Electroanal. Chem. 364 (1994) 281.

88. O. M. Magnussen, J. Hotlos, G. Beitel, D. M. Kolb and R. J. Behm, J. Vac. Sci. B 9 (1991) 969.

89. J. O’M. Bockris and A. K. N. Reddy, Modern Electrochemistry, Plenum Press, New York (1970).

90. C. W. Tindall and S. Bruckenstein, Anal. Chem. 40 (1968) 1402. 
91. A. Damjanovic, T. H. V. Setty and J. O’M. Bockris, J. Electrochem. Soc. 113 (1966) 429.

92. Ch. E. D. Chidsey, Science 251 (1991) 919.

93. H. O. Finklea and D. H. Hanshew, J. Am. Chem. Soc. 114 (1992) 3173.

94. J. F. Smalley, S. W. Feldberg, Ch. E. D. Chidsey, M. R. Linford, M. D. Newton and Y.-P. Liu, J. Phys. Chem. 99 (1995) 13141.

95. E. Bunge, R. J. Nichols, B. Roelfs, H. Meyer and H. Baumgärtel, Langmuir 12 (1996) 3060 .

96. M. R. Vogt, W. Polewska, O. M. Magnussen and R. J. Behm, J. Electrochem. Soc. 144 (1997) L113.

97. S.-L. Yau, Y.-G. Kim and K. Itaya, J. Phys. Chem. 101 (1997) 3547.

98. S. Esch, M. Hohage, T. Michely and G. Comsa, Phys. Rev. Lett. 72 (1994) 518. 